\title{
Le microbiote de moustique et son influence sur la transmission vectorielle
}

\author{
Katy $\mathrm{Heu}^{1}$ et Mathilde Gendrin ${ }^{1,2, *}$ \\ ${ }^{1}$ Groupe «Microbiote des Insectes Vecteurs », Institut Pasteur de la Guyane, Cayenne, Guyane, France \\ 2 Département «Parasites et Insectes Vecteurs », Institut Pasteur, Paris, France
}

Reçu le 20 décembre 2018

\begin{abstract}
Résumé - Les moustiques, constituant la famille des Culicidae, sont présents partout dans le monde. Parmi leurs 3500 espèces, on compte une centaine de vecteurs d'agents pathogènes pour l'homme. Ils hébergent des communautés microbiennes qui influencent notamment leur propension à transmettre ces pathogènes par inhibition directe ou en affectant l'immunité et la physiologie de leur hôte. Ces communautés microbiennes colonisent divers tissus, notamment l'appareil digestif, et varient en fonction du sexe, du stade de développement et de facteurs écologiques. Dans cette revue, nous décrivons la diversité du microbiote, incluant des bactéries, des champignons, des parasites et des virus, ainsi que ses modes d'acquisition. Nous faisons état des connaissances sur les interactions microbiennes chez le moustique, qui affectent notamment la compétence vectorielle, et sur l'effet du microbiote sur le moustique. Enfin, nous nous intéressons aux opportunités d'utilisation de microbes ou de dérivés microbiens pour lutter contre la transmission vectorielle.
\end{abstract}

Mots clés : moustiques, microbiote, parasites, arbovirus, compétence vectorielle

\begin{abstract}
Mosquito microbiota and its influence on disease vectorial transmission. Mosquitoes (Diptera: Culicidae) are found worldwide. Around 100 among 3500 mosquito species are known to be vectors of parasites and viruses, responsible for infectious diseases including malaria and dengue. Mosquitoes host diverse microbial communities that influence disease transmission, either by direct interference or via affecting host immunity and physiology. These microbial communities are present within diverse tissues, including the digestive tract, and vary depending on the sex of the mosquito, its developmental stage, and ecological factors. This review summarizes the current knowledge about the mosquito microbiota, defined as a community of commensal, symbiotic or pathogenic microbes harboured by a host. We first describe the current knowledge on the diversity of the microbiota, that includes bacteria, fungi, parasites and viruses and on its modes of acquisition throughout the mosquito life cycle. We then focus on microbial interactions within the mosquito gut, which notably affect vector competence, and on host-microbe interactions affecting mosquito fitness. Finally, we discuss current or potential methods based on the use of microbes or microbial products to interfere with pathogen transmission or to reduce mosquito lifespan and reproduction.
\end{abstract}

Keywords: mosquito, microbiota, parasites, arbovirus, vector competence

\section{Introduction}

Les moustiques, constituant la famille des Culicidae, comptent plus de 3500 espèces différentes distribuées dans le monde entier, pour la plupart hématophages. Parmi ces espèces, certaines sont capables de transmettre des agents pathogènes aux vertébrés, faisant d'eux un problème important de santé publique. Les espèces les plus décrites appartiennent aux genres Anopheles, Aedes et Culex (Becker et al., 2010). Les

\footnotetext{
*Auteur correspondant: mathilde.gendrin@pasteur.fr
}

moustiques vecteurs du genre Anopheles transmettent les parasites causant le paludisme humain et la filariose lymphatique ainsi que le virus O'nyong-nyong (van den Berg et al., 2013; Rezza et al., 2017). Les moustiques du genre Aedes et Culex sont plutôt impliqués dans les épidémies d'arbovirus (abréviation de arthropod-borne viruses, transmis par des arthropodes) tels que les virus de la Dengue, du Chikungunya ou encore Zika (Patterson et al., 2016). Comme la plupart des organismes multicellulaires, les moustiques sont hôtes d'une communauté de microbes commensaux, symbiotiques ou pathogènes, le microbiote. Ces microbes, incluant des bactéries, des virus, 
des champignons, des protozoaires, des nématodes et des acariens, sont présents de façon plus ou moins stable au sein de l'exosquelette, de l'intestin, de l'hémocœle et/ou dans les cellules du moustique. Connaître la structure du microbiote est un prérequis pour comprendre comment fonctionne l'écosystème qu'il constitue au sein du moustique mais également comment il interagit avec celui-ci. Le microbiote de moustique fait l'objet d'un intérêt particulier du fait de son influence sur certains facteurs déterminant la capacité du moustique à transmettre des agents pathogènes: l'immunité, la longévité, la fécondité, et le métabolisme. Parmi les tissus abritant un microbiote, l'intestin est un site primordial pour la propagation de pathogènes. Le moustique est en effet infecté par ingestion de sang contaminé, qui est conservé dans l'intestin pendant environ deux jours de digestion au cours desquels le microbiote bactérien se multiplie. Les arbovirus ingérés se multiplient dans les cellules épithéliales de l'intestin avant de se propager dans d'autres tissus, en particulier les glandes salivaires, via l'hémolymphe. Le parasite du paludisme, Plasmodium, se développe dans la lumière intestinale puis s'enkyste sous l'épithélium intestinal et libère, après maturation, des parasites mobiles capables d'infecter les glandes salivaires.

Tous les moustiques ont une phase aquatique durant leurs stades juvéniles (œufs, larves et pupes) puis une phase aérienne pour les adultes (Figure 1). Les larves consomment des détritus organiques, des organismes unicellulaires et de petits invertébrés alors que les adultes se nourrissent de nectars floraux. Chez la plupart des espèces de moustiques (dits anautogéniques), les femelles adultes se nourrissent aussi de sang qui leur apporte les nutriments essentiels à la production d'œufs. Les moustiques ont des rythmes circadiens variés: la majorité des espèces d'Anopheles et Culex ont une activité nocturne alors que les Aedes ont généralement une activité diurne. Ces genres diffèrent aussi par le choix d'habitat pour le site de reproduction: de façon générale, les espèces Anopheles préfèrent une eau claire et exposée au soleil alors que les Culex et Aedes sont le plus souvent trouvés dans une eau sombre contenant des matières organiques (Clements, 1992). Les moustiques sont porteurs d'une grande diversité de microbes qui varient en fonction du sexe, du stade de développement et de facteurs écologiques et infectieux que nous allons développer dans cette revue. Nous récapitulerons ensuite les différents effets du microbiote de moustique sur les pathogènes transmissibles à l'homme et sur la physiologie du moustique. Nous discuterons enfin des moyens actuels ou envisagés de lutte antivectorielle basés sur l'utilisation de microbes ou de leurs dérivés.

\section{Composition du microbiote de moustique}

Le microbiote évolue tout au long du cycle de vie du moustique. L'œuf peut contenir des bactéries intracellulaires et des virus dans son cytoplasme ainsi que des bactéries extracellulaires à la surface de son enveloppe, qui pourront être ingérées par la larve après éclosion. La larve acquiert également des microbes provenant de son environnement aquatique, dont certains ont été ensemencés par la femelle lors de la ponte. La larve élimine une grande partie de son microbiote intestinal juste avant de se transformer en pupe et amorcer la métamorphose, les adultes émergent donc avec très peu de microbes dans l'intestin (Moll et al., 2001). Cependant, cette stérilisation intestinale n'est que partielle, puisque des études réalisées sur des larves d'Aedes et d'Anopheles ont montré qu'une portion de leur microbiote est transmise aux adultes, y compris si la surface externe des pupes est artificiellement stérilisée (Coon et al., 2014; Chavshin et al., 2015; Duguma et al., 2015). Les adultes acquièrent également un microbiote en absorbant l'eau de leur gîte larvaire lors de l'émergence (Lindh et al., 2008) et probablement en s'alimentant de nectar floral (Lindh et al., 2008; Crotti et al., 2010; Wang et al., 2011).

$\mathrm{Au}$ cours de la vie de l'adulte, le microbiote change, on observe notamment une forte augmentation de la charge bactérienne et une diminution de la diversité du microbiote bactérien après le repas de sang (Wang et al., 2011). Le sang des vertébrés contient lui-même très peu ou pas de microbes, mais altère le métabolisme et le statut rédox (Gaio Ade et al., 2011; Oliveira et al., 2011; Gimonneau et al., 2014; Short et al., 2017). Chez le moustique, au cours du processus de digestion, différentes hydrolases sont produites dans l'intestin antérieur et postérieur ce qui constitue une pression de sélection pour les bactéries résidentes (Nation, 2016). La composition et la distribution des nutriments ingérés peuvent elles-mêmes être également une contrainte pour les bactéries. Par exemple, une concentration élevée en carbohydrates et un $\mathrm{pH}$ acide (de 5,2 à 6,5 ) dans le jabot constituent une sélection pour certains taxons bactériens (Gusmao et al., 2007; Kumar et al., 2010). La digestion du sang par les femelles serait favorisée par la présence de bactéries hémolytiques. Les agents pathogènes transmis par les moustiques affecteraient la composition du microbiote intestinal par des mécanismes encore mal connus (Muturi et al., 2016; Ramirez et al., 2017; Rodgers et al., 2017; Villegas et al., 2018).

Enfin, certains microbes peuvent être transmis horizontalement entre moustiques, par contamination de l'eau pendant le développement et par voie sexuelle chez l'adulte (Favia et al., 2007). Le sexe du moustique est un facteur déterminant de la composition du microbiote, mâle et femelle ayant des comportements écologiques différents. En effet, tous les moustiques se nourrissent de nectar et sont capables d'hydrolyser le sucrose mais seules les femelles sont hématophages (Foster, 1995). Zouache et al. (2011) ont montré qu'environ la moitié de la diversité bactérienne d'une population d'Aedes albopictus de terrain était expliquée par le sexe du moustique avec une plus grande diversité chez les femelles. L'effet du sexe a également été rapporté chez Anopheles stephensi où les bactéries du genre Bacillus et Staphylococcus ont été détectées chez les mâles alors que celles du genre Chryseobacterium, Pseudomonas et Serratia étaient, dans 


\section{Adulte:}

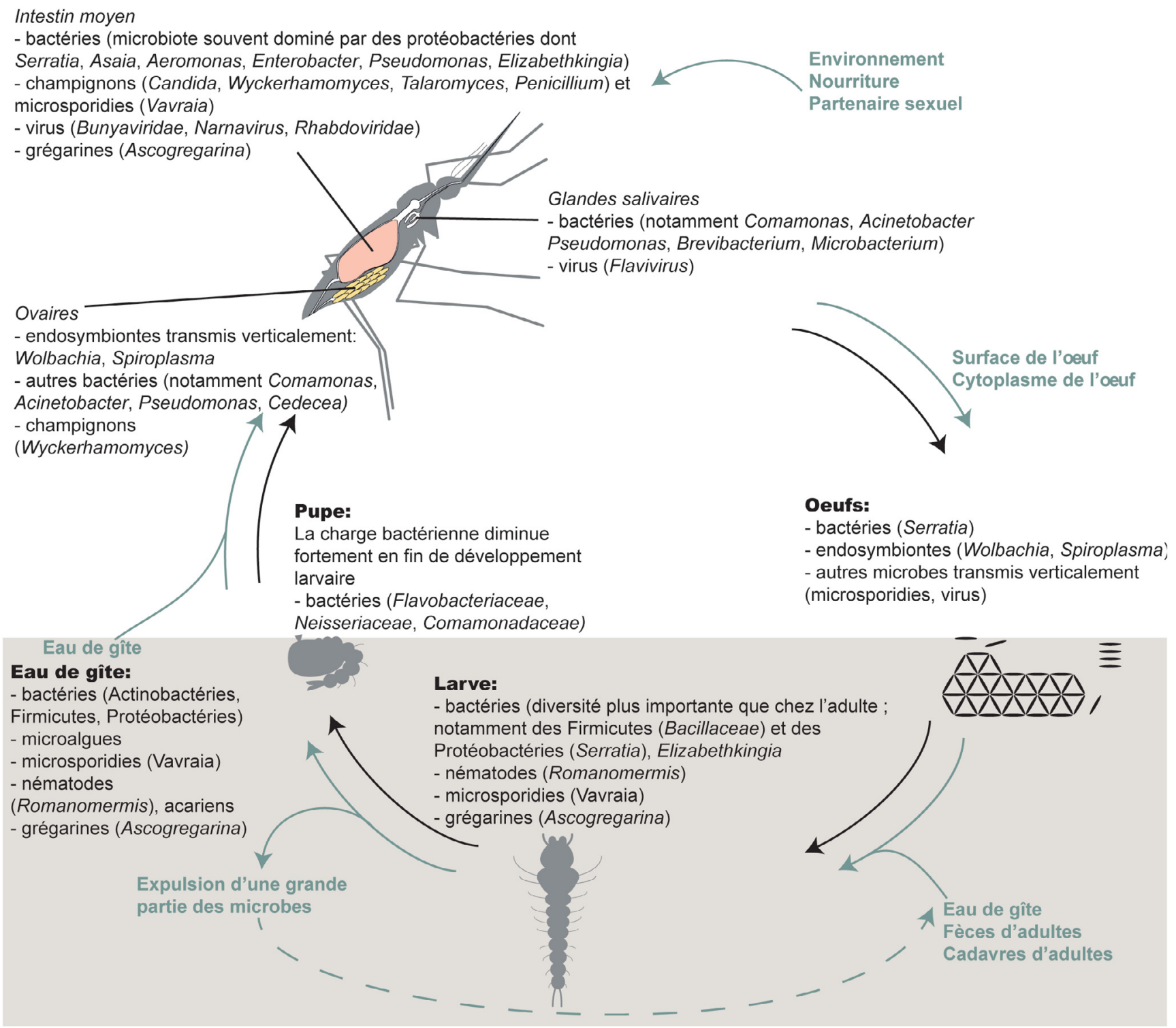

Figure 1. Microbiote du moustique au cours de son cycle de développement. Les listes de microbes ne sont pas exhaustives et fournies à titre d'exemple.

la même étude, présentes spécifiquement chez les femelles (Rani et al., 2009). Les moustiques mâles auraient un microbiote qui resterait proche de celui du gîte larvaire (Foster, 1995).

\section{Les bactéries extracellulaires}

Les données sur la composition bactérienne du microbiote proviennent en grande partie des études métagénomiques du gène de l'ARN ribosomique $16 \mathrm{~S}$ (ARNr 16S). Constitué en grande partie de bactéries aérobies ou anaérobies facultatives, le microbiote bactérien de moustique peut également être étudié par des méthodes de culture (Gusmao et al., 2010 ; Coon et al., 2014; Dickson et al., 2017). La majorité des bactéries identifiées sont à Gram négatif et appartiennent en grande partie à quatre phyla: Protéobactéries, Firmicutes, Bacteroidetes et Actinobactéries (Strand, 2018). Chez Anopheles, plus de 100 genres bactériens ont été identifiés, seuls certains d'entre eux étant fréquemment détectés, notamment Pseudomonas, Aeromonas, Asaia, Elizabethkingia, Enterobacter, Klebsiella, Pantoea et Serratia (Gendrin \& Christophides, 2013). Au sein d'un individu, le microbiote bactérien est peu complexe et peu influencé par l'espèce de moustique: une étude de séquençage réalisée sur des moustiques collectés au Kenya rapporte notamment que 4 espèces bactériennes représentent en moyenne $90 \%$ du microbiote (Osei-Poku et al., 2012 ; Gimonneau et al., 2014; Akorli et al., 2016). 
La fréquence avec laquelle sont retrouvés un petit nombre de genres bactériens dans les populations de moustiques a fait naître le concept d'un microbiote-cœur, partagé par des populations de moustiques de diverses espèces et/ou collectées dans des zones géographiques distinctes (Segata et al., 2016; Astudillo-Garcia et al., 2017). Par exemple, une étude a montré que les genres Pseudomonas, Acinetobacter et Aeromonas étaient retrouvés dans différentes populations d'Aedes aegypti du Brésil (David et al., 2016). Notons cependant qu'aucune bactérie n'est systématiquement associée au microbiote de moustique, ce qui suggère l'absence de microbiotecour strictement conservé. Récemment, a été mis en évidence le fait que les interactions entre bactéries jouent un rôle majeur dans la détermination de la composition du microbiote, certains genres bactériens étant fréquemment trouvés chez le même moustique alors que d'autres s'excluent mutuellement ou co-existent tout en excluant un troisième taxon (Hegde et al., 2018). Ces données suggèrent qu'au lieu d'un seul microbiote-cour, plusieurs microbiotes typiques pourraient exister et être déterminés selon la composition microbienne de l'environnement et les interactions microbiennes au sein du moustique.

La composition du microbiote a été analysée dans plusieurs tissus. Chez Anopheles gambiae et An. coluzzii, les genres Staphylococcus, Corynebacterium, Geobacillus, Micrococcus, Acinetobacter et Pseudomonas sont présents dans les organes reproducteurs mâles et femelles (Segata et al., 2016). Les genres Pseudomonas, Comamonas, Acinetobacter, Rhizobium et Burkholderia ont été détectés à la fois dans les ovaires, les glandes salivaires et l'intestin d'Anopheles (Tchioffo et al., 2015). Récemment, une étude de la distribution du microbiote dans divers tissus rapporte que les glandes salivaires possèdent un microbiote plus complexe et divers que celui retrouvé dans l'intestin (Sharma et al., 2014; Mancini et al., 2018). L'hémolymphe est le plus souvent un liquide exempt de bactéries (Dobson et al., 1999).

\section{Les endosymbiontes: Wolbachia et Spiroplasme}

Chez certains moustiques, comme chez de nombreuses espèces d'arthropodes, deux taxons majeurs d'endosymbiontes facultatifs ont été identifiés: Wolbachia et Spiroplasma. Ces bactéries étant transmises verticalement par la mère, elles ont acquis la particularité de modifier la reproduction de leur hôte, augmentant ainsi leur propagation, par des mécanismes variables selon l'espèce d'arthropode et la souche bactérienne. Ainsi, Wolbachia induit une incompatibilité cytoplasmique, les spermatozoïdes des mâles infectés ne pouvant pas fertiliser les ovocytes de femelles non infectées. Cela favorise la reproduction des femelles infectées par rapport aux femelles non infectées au sein d'une population. Ces bactéries peuvent également augmenter la proportion de femelles dans une population par induction de parthénogénèse, par létalité mâle-spécifique au cours du développement ou par féminisation des mâles (Werren et al., 2008).
Wolbachia est une bactérie intracellulaire infectant notamment les ovaires, mais également trouvée dans la tête, les muscles, les tubes de Malpighi et les testicules chez Culex pipiens et Ae. albopictus (Dobson et al., 1999; Zouache et al., 2009). Alors que le genre Anopheles a d'abord été considéré comme exempt d'infection par Wolbachia, des infections naturelles par Wolbachia ont été détectées chez plusieurs espèces d'Anopheles. Spiroplasma est une bactérie hélicoïdale, sans paroi, transmise à la fois verticalement et horizontalement (Haselkorn et al., 2009). Elle peut être extracellulaire ou intracellulaire, elle est notamment capable de se multiplier dans l'hémolymphe et être incluse par endocytose dans les ovocytes de son hôte (Herren et al., 2013). Récemment, Spiroplasma insolitum a été identifié chez $A n$. Gambiae. Cette espèce à haute efficacité de transmission maternelle ne semble pas pathogène pour l'hôte (Chepkemoi et al., 2017).

\section{Les eucaryotes du microbiote}

Des eucaryotes unicellulaires incluant des levures, champignons, algues et Apicomplexa ont été identifiés dans le microbiote de diverses espèces de moustiques (Chandler et al., 2015; Muturi et al., 2016; Steyn et al., 2016 ; Belda et al., 2017 ; Bozic et al., 2017 ; Thongsripong et al., 2018). Chez Culex pipiens et Cx. theileri, les levures des genres Candida, Cryptococcus, Galactomyces, Hannaella, Meyerozyma, Pichia, Rhodosporidium, Rhodotorula, Trichosporon et Wickerhamomyces ont été identifiées à partir de larves et moustiques adultes (Steyn et al., 2016). Une étude sur des espèces de moustiques d'élevage a montré l'identification par culture de quatre espèces de levures d'intérêt clinique: Meyerozyma guilliermondii, Rhodotorula glutinis, Sporobolomyces cf. roseus et Candida parapsilosis. Il est donc envisageable que ces moustiques contribuent à leur dissémination environnementale (Bozic et al., 2017). Chez beaucoup d'invertébrés, les champignons symbiontes sont connus pour fournir des suppléments nutritionnels (Douglas, 2009; Moran \& Jarvik, 2010) ou encore émettre des volatiles servant comme signaux d'oviposition (Kajimura \& Hijii, 1992; Ranger et al., 2018). Les champignons associés aux moustiques sont relativement peu étudiés par rapport aux bactéries. La plupart des études réalisées sur les champignons des moustiques se sont concentrées sur les champignons entomopathogènes et leur utilisation dans la lutte antivectorielle (Scholte et al., 2004). Plus de 1000 espèces distribuées dans les phyla Entomophthoromycètes, Blastocladiomycètes, Microsporidies, Basidiomycètes et Ascomycètes sont connues pour infecter et tuer les insectes (Vega et al., 2012). Les spores de ces champignons s'attachent au tégument de façon passive et non spécifique, puis germent et pénètrent la cuticule. Une fois dans l'hémocœle, le mycélium croît à travers l'hôte, produit des destruxines qui le paralysent et tue l'insecte en 3 à 14 jours (Farenhorst \& Knols, 2007).

Les Microsporidies constituent un groupe divers de champignons associés aux moustiques. Dans le monde, 14 genres différents ont été décrits et il est vraisemblable 
que toutes les espèces de moustiques servent d'hôte à une ou plusieurs microsporidies (Andreadis, 2007). On distingue deux grands types de microsporidies qui diffèrent dans leur cycle de vie. D'une part, les microsporidies monomorphiques ont un développement asexuel qui produit une spore pouvant être transmise verticalement et infectant la larve de moustique par voie orale. Elles touchent un large spectre d'hôtes, sont moyennement pathogènes pour les moustiques et induisent une faible mortalité larvaire. Par exemple, Vavraia culicis affecte la reproduction et la longévité des moustiques adultes mais a peu d'effet chez la larve, et sa présence serait négativement corrélée avec celle de Plasmodium (Ang'Ang'O, 2018). D'autre part, les microsporidies polymorphiques sont plus communes et ont des cycles de vie complexes, combinant reproduction sexuée et asexuée. Elles sont transmises verticalement et horizontalement, leurs spores infectant divers stades de développement de l'hôte et divers tissus. Beaucoup d'espèces telle que Edhazardia aedis requièrent deux générations d'hôtes successives pour compléter leur cycle de vie et au moins 4 genres, Amblyospora, Duboscqia, Hyalinocysta et Parathelohania, exigent obligatoirement un développement dans un hôte intermédiaire copépode. Les microsporidies polymorphiques ont un niveau plus élevé de spécificité d'hôtes et affectent peu la fitness de leur hôte, qui les transmet par voie transovarienne. E. aedis diminuerait la longévité et la fécondité des femelles (Ang'Ang'O, 2018).

Les moustiques sont également porteurs de grégarines, parasites exclusifs d'invertébrés, appartenant au phylum Apicomplexa. À ce jour, neuf espèces de grégarines du genre Ascogregarina ont été décrites chez les moustiques (Lantova \& Volf, 2014). Les grégarines infectent l'intestin larvaire et sont conservées jusqu'à l'âge l'adulte, voire transmises à la descendance selon les espèces. Chez l'adulte, elles se développent dans les tubes de Malpighi et les stades oocystes, infectieux pour les larves, sont déféqués (Lantova \& Volf, 2014). Ascogregarina culicis est infectieux à tous les stades larvaires chez Ae. aegypti, avec une efficacité variable selon la provenance géographique des souches (Reyes-Villanueva et al., 2003). Par exemple, la souche d'Ae. aegypti de Trinidad n'est pas susceptible à la souche d'As. culicis de Floride (Beier et al., 1995). As. culicis a également été décrite chez Ae. geniculatus, Ae. albopictus, Ae. koreicus et Ae. polynesiensis. Plusieurs espèces de grégarines ont été identifiées chez Aedes avec des prévalences de 3 à $100 \%$, en particulier As. barretti, As. clarki, As. lanyuensis, As. taiwanensis et As. geniculati (Lantova \& Volf, 2014). En termes de spécificité d'hôte, As. taiwanensis infecte à $100 \%$ les larves d'Ae. aegypti et Aedes taeniorhynchus mais pas les espèces de Culex et d'Anopheles testées (Garcia et al., 1994). Des infections expérimentales croisées peuvent cependant être réalisées entre grégarines de plusieurs espèces d'Aedes et aboutir à la production d'oocystes chez un hôte inhabituel (Munstermann \& Wesson, 1990). L'infection d'A e. aegypti par $A$ s. culicis augmente la mortalité larvaire sans affecter le temps de développement larvaire, la taille, le poids des pupes et le taux d'émergence des adultes (McCray et al.,
1970 ; Sulaiman, 1992) As. barretti réduit le poids des pupes femelles, prolonge le développement des mâles et augmente la mortalité pupale (Beier \& Harris, 1983 ; Siegel et al., 1992) mais n'altère pas la survie des adultes, mâles et femelles (Walker et al., 1987). Enfin, As. taiwanensi serait également capable d'attirer les femelles gravides d'Ae. aegypti à pondre leurs œufs dans l'eau où il se trouve (Reeves, 2004). Les effets des grégarines sur les moustiques peuvent être altérés en cas de co-infection par d'autres parasites.

Les Mermithidés sont des vers nématodes endoparasites des arthropodes. Leurs stades juvéniles sont retrouvés dans les gîtes larvaires de moustiques. Le genre le plus connu est Romanomermis qui compte 14 espèces parasites du moustique. Le stade juvénile du parasite entre dans l'hémocœle de la larve en pénétrant la cuticule. Le parasite se développe dans l'hôte, déplétant ainsi ses nutriments, puis le tue et tombe au fond du gîte larvaire où il mue deux fois et devient adulte. Après accouplement, les femelles pondent des œufs dans le sol du gîte larvaire (Platzer, 2007).

Les acariens d'eau (Acari: Parasitengona: Hydrachnidiae) sont un groupe d'invertébrés d'eau douce abondants, divers et ubiquitaires. Leur cycle de vie typique comprend des larves parasites, des deutonymphes (stade de développement précédant le stade adulte) et des adultes prédateurs, séparés par des stades de transformation au repos. Au total, 105 espèces de moustiques, appartenant entre autres aux genres Aedes, Anopheles, Culex, Coquillettidia ou encore Mansonia, ont été décrites comme parasitées par des acariens d'eau (Simmons \& Hutchinson, 2016). Dans des conditions de laboratoire, les acariens d'eau réduisent la fécondité et la longévité de leurs hôtes (Smith \& McIver, 1984). Les interactions moustiquesacariens ont été étudiées pour comprendre les relations biologiques de bases d'ectoparasite-hôte, l'impact des acariens sur la survie et la fécondité des individus et évaluer leur potentiel de biocontrôle des populations de moustiques (Esteva et al., 2006).

\section{Les virus}

Des études métagénomiques ont permis d'identifier un certain nombre de virus de moustiques qui appartiennent essentiellement aux familles Bunyaviridae, Birnaviridae, Flaviviridae, Mesonoviridae, Negoviridae, Reoviridae, Rhabdoviridae et Togaviridae (Bolling et al., 2015; Vasilakis \& Tesh, 2015; Roundy et al., 2017). Parmi ces virus, certains sont connus pour être transmissibles aux vertébrés et appelés arbovirus, les autres sont dits «insectes-spécifiques». Parmi ces derniers, on compte notamment le Flavivirus «Cell fusing agent», isolé par culture de cellules d'A e. aegypti (Stollar \& Thomas, 1975). Quelques virus du genre Alphavirus sont également décrits, en particulier le virus Eilat (EILV) chez Anopheles coustani en Israël et le virus Taï Forest chez Culex decens en Côte d'Ivoire (Nasar et al., 2012; Hermanns et al., 2017). De même que certaines bactéries, ces virus sont transmis verticalement, comme par exemple Culex 
flavivirus et Aedes flavivirus, respectivement chez Culex pipiens et Ae. albopictus (Saiyasombat et al., 2011; Haddow et al., 2013). Une transmission horizontale et inter-espèces peut également avoir lieu pour certains virus qui peuvent être détectés chez différentes espèces de moustiques d'une même zone géographique. Les mécanismes de transmission ne sont pas encore clairs, en particulier aucune transmission horizontale n'a été détectée en laboratoire entre des Culex pipiens infectés ou non infectés avec Culex flavivirus, bien qu'élevés dans la même cage et avec la même source d'aliments (Bolling et al., 2012). La transmission de certains virus pourrait peut-être impliquer des plantes. En effet, des adultes se nourrissant de nectar pourraient contaminer des plantes ou acquérir des virus à partir de plantes contaminées (Roossinck et al., 2015; Roundy et al., 2017). Cependant, si les virus de plantes sont transmis par des insectes vecteurs spécifiques, il n'y a pas encore de données concernant la détection de virus dits «insectes-spécifiques» chez les plantes (Whitfield et al., 2015). L'infection des glandes salivaires est une condition essentielle au maintien des arbovirus mais n'est observée que pour certains virus dits «insectes-spécifiques». Par exemple, Aedes flavivirus est détecté dans la salive d'Ae. albopictus alors que le virus «Cell fusing agent» ne l'est pas dans la salive et les glandes salivaires d'Ae. aegypti et Culex annulirostris (Halbach et al., 2017).

\section{Les pathogènes transmissibles}

Parmi les divers taxons colonisant le moustique, certains agents sont transmissibles aux vertébrés, notamment à l'homme. Nous avons fait le choix de rassembler ces pathogènes d'importance en santé publique dans les paragraphes qui suivent. Cependant, comme nous utilisons ici l'acception large du terme «microbiote», de plus en plus commune, ils font partie intégrante du microbiote comme tous les autres microbes abrités par le moustique.

\section{Parasites}

Plasmodium (Apicomplexa: Haemosporida) et Filarioidea (Nematoda: Spirurida)

Parmi les 150 espèces de Plasmodium qui infectent les vertébrés, seules cinq espèces sont responsables du paludisme chez l'homme: $P$. falciparum, $P$. vivax, $P$. ovale, $P$. malariae et $P$. knowlesi. Les gamétocytes (précurseurs des gamètes) de Plasmodium ingérés lors d'un repas de sang sont activés en atteignant l'intestin du moustique. La reproduction sexuée du parasite a lieu dans la lumière intestinale, puis les zygotes se différencient en ookinètes allongés et mobiles. Ces ookinètes vont traverser l'épithélium intestinal et se transformer en oocystes qui croissent, puis se rompent, libérant des sporozoïtes, mobiles, dans l'hémocoele. Ces derniers migrent dans l'hémocoele et envahissent les glandes salivaires, d'où ils vont être inoculés à de nouveaux hôtes humains durant les prochains repas sanguins. Le temps de développement du parasite chez le moustique, ou période d'incubation extrinsèque, est d'environ deux semaines (Shapiro et al., 2017).
Les agents responsables de filarioses lymphatiques chez l'homme sont Wuchereria bancrofti, (90\% des cas), Brugia malayi et Brugia timori. Leurs cycles de vie nécessitent une étape dans un moustique vecteur, Anopheles, Culex, Aedes et Mansonia, en fonction de la localisation géographique (Manguin et al., 2010). Les microfilaires (larves) sont acquises par le moustique lors du repas sanguin. Elles pénètrent la paroi intestinale jusqu'à l'hémocœle pour migrer vers le muscle thoracique où elles se développent jusqu'au $3^{\mathrm{e}}$ stade larvaire. Elles migrent ensuite jusqu'au proboscis (appendice buccal) d'où elles peuvent infecter un autre humain via la piqûre. Elles finiront leur développement dans le système lymphatique humain. Comme pour Plasmodium, la période d'incubation extrinsèque des microfilaires est d'environ 10 à 14 jours (Manguin et al., 2010).

\section{Arbovirus}

Plus de 130 arbovirus de la famille des Togaviridae, Flaviviridae, Bunyaviridae, Reoviridae et Orthomyxoviridae peuvent causer des pathologies chez l'homme. Parmi ces virus, ceux transmis par les moustiques à l'homme sont listés dans le tableau 1 (Cleton et al., 2012).

Les arbovirus sont maintenus dans les zones endémiques par des cycles de transmission entre vertébrés et arthropodes. Les arboviroses sont considérées comme d'origine zoonotique, c'est-à-dire qu'elles seraient transmises d'un animal réservoir à l'homme, mais les virus connus n'ont pas encore tous été isolés d'environnements forestiers, dits selvatiques. Généralement, les arbovirus circulent au sein d'un cycle selvatique où les virus sont transmis entre des primates non humains, ou d'autres hôtes vertébrés (rongeurs, oiseaux, ...), par des moustiques. L'Homme peut être contaminé accidentellement lors d'intrusion en zones forestières par la piqûre de moustiques infectés, assurant ainsi le transfert du virus de l'hôte vertébré selvatique à l'Homme. Une épidémie peut survenir si le virus est introduit dans un environnement permissif où cohabitent des vecteurs compétents et une population humaine (Marklewitz \& Junglen, 2018). Après ingestion du sang infecté par le moustique, le virus pénètre dans les cellules épithéliales de l'intestin où il se multiplie, puis s'échappe de l'intestin pour se disséminer dans le corps du moustique et dans d'autres tissus. En particulier, il contamine les glandes salivaires où il se multiplie et infecte la salive, pouvant être transmis à l'Homme lors des prochaines piqûres de l'insecte. La période d'incubation extrinsèque est généralement de 7 à 14 jours en fonction de la souche du virus, de la température, de l'espèce de moustique (Jupatanakul et al., 2014).

\section{Interactions entre microbes au sein du moustique}

L'intestin du moustique est un lieu d'interactions complexes entre le moustique, son microbiote et les nouveaux microbes ingérés, tels que les pathogènes humains. Dans les années 1990, il a été mis en évidence 
Tableau 1. Quelques arbovirus transmis par les moustiques et pouvant infecter l'homme.

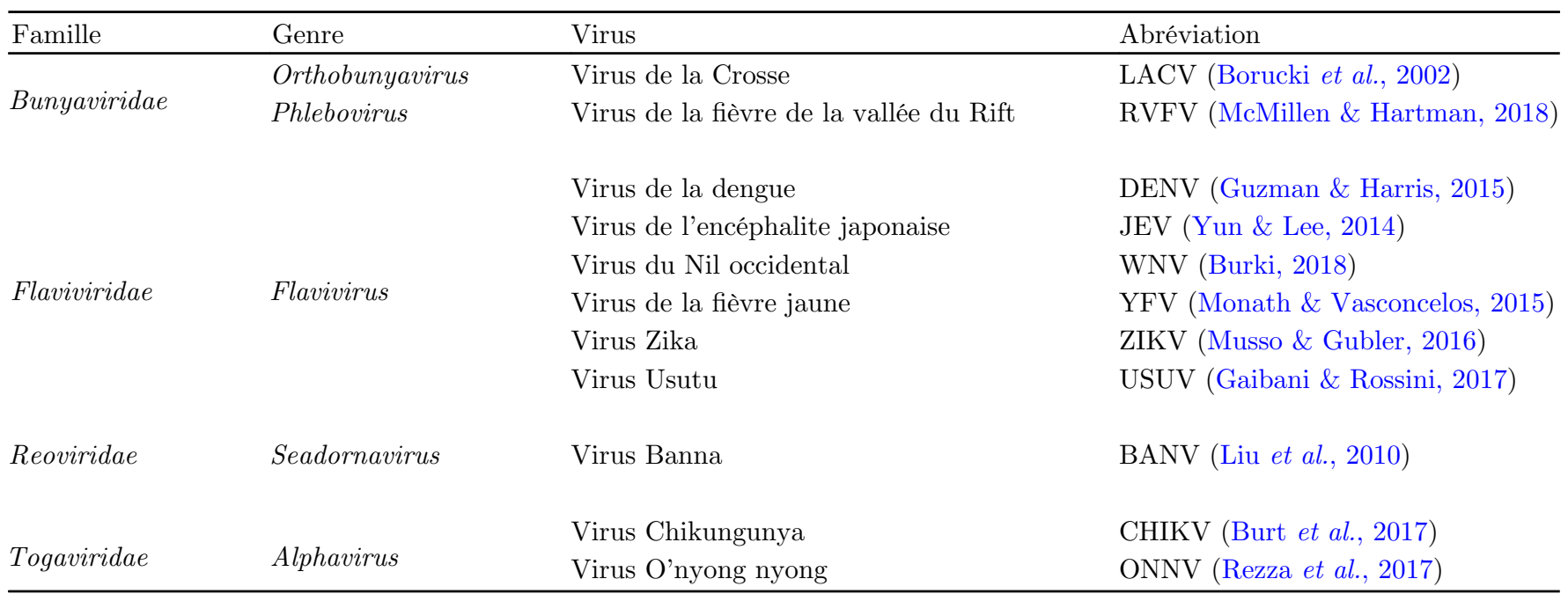

que certaines bactéries isolées du microbiote bactérien du moustique peuvent interférer avec l'infection par Plasmodium (Pumpuni et al., 1993). Au cours des deux dernières décennies, un intérêt croissant s'est porté sur l'effet du microbiote sur la capacité vectorielle du moustique et plus généralement sur les interactions microbiennes au sein du moustique.

\section{Effet par et sur les bactéries}

Chez de nombreux hôtes, le microbiote augmente la résistance d'un hôte à la colonisation par de nouveaux microbes, notamment de nouvelles bactéries. Ce phénomène est lié à l'occupation d'une niche écologique et la compétition pour l'espace et les nutriments, la stimulation du système immunitaire de l'hôte et la production de toxines (Stecher \& Hardt, 2011). Chez le moustique, la résistance à la colonisation existe, plusieurs souches bactériennes sont moins efficaces à coloniser un moustique porteur d'un microbiote (Hegde et al., 2018). La compétition entre espèces bactériennes a également été mise en évidence in vitro chez des bactéries isolées d'Ae. aegypti, Serratia marcescens inhibant la croissance de Sphingomonas et Burkholderiaceae (Terenius et al., 2012). Chez Anopheles, les bactéries Asaia et Wolbachia s'excluent mutuellement, la présence d'Asaia dans le microbiote empêcherait notamment la transmission verticale de Wolbachia (Hughes et al., 2014 ; Rossi et al., 2015).

Une telle résistance combat également l'infection par Plasmodium. En effet, chez Anopheles, l'élimination du microbiote par traitement antibiotique augmente la susceptibilité des moustiques à l'infection par Plasmodium (Pumpuni et al., 1993; Dong et al., 2009; Meister et al., 2009; Wang et al., 2013). Si cet effet est conservé pour diverses espèces d'Anopheles et de Plasmodium, il est cependant très variable selon les souches bactériennes considérées. Certaines souches bactériennes, telles qu'Enterobacter sp. EspZ ou S. marcescens HB3, rendent le moustique résistant à l'infection alors que d'autres comme
Bacillus pumilus et $S$. marcescens HB18 n'ont aucun effet (Cirimotich et al., 2011 ; Bando et al., 2013 ; Ramirez et al., 2014). Ceci suggère que la composition du microbiote est déterminante pour la compétence vectorielle du moustique, c'est-à-dire sa permissivité au développement du parasite. Une corrélation positive entre l'abondance de la famille Enterobacteriaceae dans l'intestin et le statut d'infection par Plasmodium a par exemple été observée dans une étude (Boissière et al., 2012). Cette corrélation n'est pas généralisée mais suggère qu'il est nécessaire de prendre en compte la composition du microbiote dans les études fonctionnelles. Les mécanismes anti-Plasmodium sont à la fois directs, par production d'espèces réactives de l'oxygène, de cyanure ou de molécules antimicrobiennes, ou indirects, par stimulation de l'immunité du moustique (Meister et al., 2009 ; Cirimotich et al., 2011; Ramirez et al., 2014; Romoli \& Gendrin, 2018) (Figure 2). Les premiers sont souches-spécifiques alors que les seconds sont plus généralistes, car l'immunité est induite par détection du peptidoglycane bactérien, un composant majeur de la paroi bactérienne. L'effet antiparasitaire de $S$. marcescens HB3 dépendrait de la présence d'une voie fonctionnelle de synthèse du flagelle, la motilité des bactéries jouant potentiellement un rôle majeur dans ce phénomène d'inhibition (Bando et al., 2013).

Comme cela a d'abord observé chez la drosophile, certaines souches de Wolbachia confèrent une forte résistance des moustiques aux infections virales. Chez Culex pipiens naturellement infecté par Wolbachia, la charge virale du virus du Nil occidental est réduite de 2 à 3 fois par rapport à celle des individus non infectés par Wolbachia (Glaser \& Meola, 2010). Chez la lignée ALPROV d'Ae. Albopictus, porteuse naturellement de deux souches de Wolbachia, wAlbA et wAlbB, le virus se réplique mais la présence de particules virales dans les glandes salivaires est réduite (Mousson et al., 2012). Une corrélation négative entre la présence de Wolbachia et l'infection par Plasmodium falciparum a également été mise en évidence (Baldini et al., 2014; Shaw et al., 2016; Gomes 


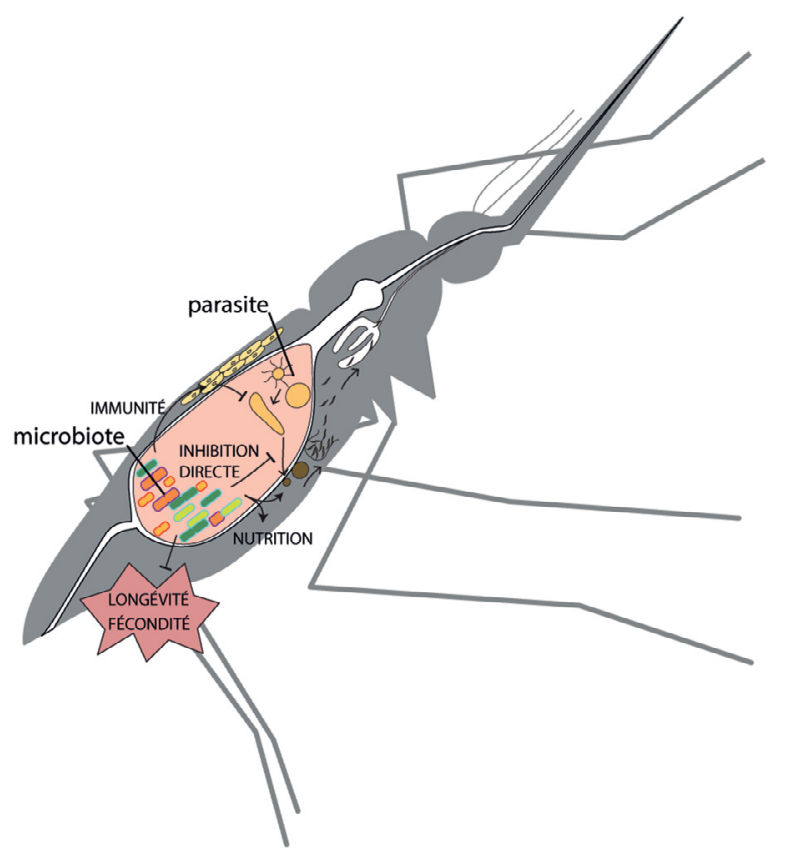

Figure 2. Effet du microbiote sur la capacité vectorielle du moustique.

et al., 2017). Wolbachia n'affecterait pas l'infection lors des phases précoces mais aurait un effet négatif sur la présence de sporozoïtes dans les glandes salivaires (Gomes et al., 2017). Les mécanismes par lesquels les bactéries interfèrent avec la compétence vectorielle restent encore à déchiffrer mais des hypothèses ont été suggérées. Comme les bactéries et pathogènes envahissent les mêmes tissus ou éventuellement les mêmes cellules, une compétition pour les ressources en cholestérol et acides aminés a été avancée (Caragata et al., 2013, 2014). La présence des bactéries peut induire une réponse immunitaire dont les composés peuvent interagir directement avec les pathogènes. L'inhibition du virus de la dengue par Wolbachia serait corrélée avec une induction du stress oxydatif chez Ae. aegypti (Pan et al., 2012). Cela résulte d'une activation de la voie de signalisation Toll aboutissant à la production de molécules antioxydantes et de peptides anti-microbiens (défensine et cécropines) agissant contre le virus de la dengue.

Inversement, la diversité et la composition du microbiote bactérien peuvent être modifiées à la suite d'une infection. Par exemple, l'abondance d'Enterobacteriaceae chez Ae. albopictus augmenterait avec l'infection par le virus Chikungunya alors que celle d'autres bactéries comme Wolbachia et Blattabacterium diminuerait (Zouache et al., 2012). Chez Aedes japonicus et Aedes triseriatus infectés par le virus de La Crosse, il a été rapporté que la quantité de bactéries augmentait alors que la richesse des champignons présents diminuait (Muturi et al., 2016). Dans le cas de moustiques infectés par le virus de la Dengue, une réduction de la quantité de bactéries a été observée (Ramirez et al., 2012). Les infections par le virus Zika moduleraient également les dynamiques des familles bactériennes Rhodobacteraceae et Desulfuromonadaceae chez Ae. aegypti (Villegas et al., 2018).

\section{Effet des virus insectes-spécifiques}

Des études ont montré qu'un flavivirus dit «insectespécifique», le virus Nhumirim, était capable de supprimer la croissance du virus du Nil occidental et de diminuer son taux de transmission par Culex quinquefasciatus (Goenaga et al., 2015). Récemment, le virus Nhumirin a été testé chez Ae. albopictus et montre également un effet inhibiteur sur les virus du Zika, de la Dengue et Chikungunya (Romo et al., 2018). À partir de cultures de cellules C6/36 d'Ae. albopictus, il a été montré que la co-infection du virus du Nil occidental et Culex flavivirus isolé du Colorado conduit également à une diminution de la réplication du virus du Nil occidental (Bolling et al., 2012). La réplication du virus de l'encéphalite japonaise et celle du virus du Nil occidental en cellules C6/36 diminuent également lors de co-infections avec le virus Nhumirim (Kenney et al., 2014; Goenaga et al., 2015). Eilat virus aurait également un effet négatif sur la réplication du virus Chikungunya en cellules d'Ae. albopictus $\mathrm{C} 7 / 10$ et sa dissémination chez des moustiques Ae. aegypti (Nasar et al., 2012). Au contraire, la souche Culex flavivirus du Japon faciliterait l'infection par le virus de la dengue et du virus de l'encéphalite japonaise dans des cellules de Culex tritaeniorhynchus (Kuwata et al., 2015). Selon les combinaisons de lignées cellulaires, de souches de virus dits «insectesspécifiques » et d'arbovirus, les co-infections peuvent donc aboutir à des résultats variables, une diminution de l'infection arbovirale étant plus fréquemment observée.

\section{Effet des parasites et des champignons}

Une étude suggère que la grégarine As. culicis favoriserait l'infection du vecteur par le virus Chikungunya: une forte infection par As. sulicis rendrait les larves d'Ae. aegypti permissives au virus Chikungunya en cas d'ingestion de carcasses de moustiques porteurs. Le virus persisterait alors de façon trans-stadiale jusqu'au stade adulte (Mourya et al., 2003).

Certaines levures peuvent, via un hôte, interagir directement avec les parasites. Par exemple, Wickerhamomyces produit une toxine anti-plasmodiale in vitro alors que Penicillium chrysogenum favorise l'infection par Plasmodium en supprimant la réponse immunitaire innée de l'hôte (Anglero-Rodriguez et al., 2016; Valzano et al., 2016). Muturi et al. (2016) ont montré que la levure Meyerozyma dominait la communauté fongique en réponse aux infections par le virus de la Crosse chez des femelles $A e$. triseriatus et Ae. Japonicus. Des facteurs sécrétés par le champignon Talaromyces régulent négativement les enzymes de digestion de son hôte naturel Ae. Aegypti, ce qui favorise l'infection par le virus de la dengue (AngleroRodriguez et al., 2017).

\section{Effet du microbiote sur la valeur sélective du moustique}

\section{Chez les stades immatures}

Le microbiote joue un rôle majeur dans le développement du moustique. Dès la fin du stade embryonnaire, des 
bactéries présentes au niveau du gîte larvaire peuvent sécréter des composants solubles capables de stimuler l'éclosion des œufs d'A e. aegypti (Ponnusamy et al., 2011). $\mathrm{Au}$ stade larvaire, plusieurs études rapportent que les larves de moustiques montrent une plus forte mortalité et/ou un retard de croissance au stade pupal quand la quantité de microbes dans le gîte larvaire est réduite (Rozemoon, 1935; Chao et al., 1963 ; Coon et al., 2016b). Plus récemment, l'augmentation de la mortalité et le retard de croissance ont également été montrés lorsque les larves sont traitées avec des antibiotiques, cet effet pouvant être compensé par l'ajout d'Asaia (Wotton et al., 1997; Chouaia et al., 2012). Coon et al. (2014) ont montré que des larves axéniques (exemptes de bactéries) d'Ae. aegypti étaient incapables de se développer au-delà du premier stade larvaire et survivaient plusieurs jours sans se développer. Leur développement jusqu'au stade adulte peut être rétabli par recolonisation artificielle d'une souche bactérienne, qu'elle soit naturellement résidente de l'intestin du moustique (par exemple, Acinetobacter, Aeromonas ou Paenibacillus) ou étrangère (Escherichia coli). La composition du microbiote bactérien influence le temps de développement larvaire et la taille de l'adulte (Dickson et al., 2017).

En étudiant comment les bactéries pouvaient promouvoir le développement larvaire, Coon et al. (2017) ont observé que le développement n'était pas rétabli par des bactéries mortes ni par des bactéries déficientes pour la respiration aérobie. Ils ont également révélé que des larves d'Ae. aegypti inoculées avec un mélange de bactéries ou avec une souche de $E$. coli montraient un niveau d'oxygène plus faible dans l'intestin (hypoxie) par rapport à des larves axéniques ou gnotobiotiques avec des bactéries déficientes de la respiration aérobie (Coon et al., 2017). Leur modèle suggère que, dans l'intestin, les bactéries induisent une réponse à l'hypoxie intestinale qui fonctionnerait comme un signal de croissance. Une étude fonctionnelle provenant du même laboratoire indique que l'hypoxie intestinale active des facteurs de transcription chez les larves d'Ae. Aegypti, induisant la voie de signalisation de l'insuline (Valzania et al., 2018). Une analyse de transcriptome a identifié des gènes régulés en présence de microbiote. Par exemple, certaines peptidases sont sous-exprimées dans l'intestin de larves d'Ae. aegypti axéniques par rapport à des larves non stériles, et plusieurs transporteurs d'acides aminés sont surexprimés (Vogel et al., 2017).

Cependant, Correa et al. (2018) ont rapporté que des larves d'Ae. aegypti pouvaient se développer jusqu'au stade adulte en absence de bactéries vivantes. En absence de bactéries vivantes, le développement larvaire est cependant ralenti et la fécondité des femelles provenant de ces larves est réduite. Ces résultats suggèrent que l'hypoxie ne serait pas nécessaire au développement larvaire, et que le rôle des bactéries serait au contraire d'apporter des nutriments nécessaire au développement de leur hôte. Ces deux modèles contradictoires sont très récents, le rôle exact du microbiote sur le développement larvaire n'est donc pas encore clair.

\section{Chez l'adulte}

Une autre étude a montré qu'E.coli 444ST95, isolée d'intestins d'Anopheles, est capable de diminuer à la fois la survie des moustiques et le développement des parasites Plasmodium. L'hémolysine F et d'autres toxines libérées par les bactéries sont des facteurs de virulence associés à cet effet (Tchioffo et al., 2016).

Le microbiote bactérien aurait également une fonction nutritionnelle. Par exemple, Serratia et Enterobacter, qui contiennent des enzymes hémolytiques, joueraient un rôle dans la digestion du sang (Campbell et al., 2004 ; Gusmao et al., 2010; Benoit et al., 2011). Chez Ae. albopictus, Acinetobacter baumannii et johnsonii, elles pourraient être impliquées dans la digestion du sang et de sources d'alimentation végétales (Minard et al., 2013). En effet, des souches d'Acinetobacter isolées de moustiques peuvent métaboliser l'acide $\alpha$-kéto-valérique et la glycine, composants du sang, ainsi que l'acide 4-hydroxy-benzoïque et le xylose, composants de la sève. Aussi, Asaia bogorensis, isolée chez An. Stephensi, pourrait fournir les moustiques en vitamines puisqu'elle est capable de les synthétiser même si l'absence de cette association n'est pas préjudiciable au moustique (Crotti et al., 2010).

Les microsporidies peuvent moduler la prise de repas sanguin. En effet, des Ae. aegypti infectés par E. aedis ont un taux du repas de sang augmenté ou réduit selon qu'ils ont été infectés par voie verticale ou horizontale, respectivement (Koella \& Agnew, 1997 ; Barnard et al., 2007). Par ailleurs, des femelles infectées par E. aedis seraient plus sensibles à l'effet répulsif du DEET (Barnard et al., 2007).

Chez An. coluzzii, le microbiote intestinal est également requis pour la formation de la matrice péritrophique, une structure acellulaire composée de chitine et de protéines, située entre la lumière intestinale et l'épithélium et synthétisée à la suite du repas de sang (Rodgers et al., 2017). Une matrice péritrophique artificiellement malformée permet aux bactéries d'être au contact des cellules intestinales, ce qui semble augmenter le risque d'infections systémiques par des microbes intestinaux (Rodgers et al., 2017).

Le microbiote joue également un rôle dans la production des œufs. Notamment, Coon et al. (2016a) ont étudié cet effet par génération de moustiques gnotobiotiques chez Aedes atropalpus, une espèce de moustique pouvant donner une première ponte sans repas sanguin. Les moustiques porteurs d'une souche bactérienne produisent généralement moins d'œufs que les moustiques élevés conventionnellement, sauf s'ils portent une souche de Comamonas qui restaure la formation d'œufs au même niveau des moustiques contrôles (Coon et al., 2016a). Le microbiote d'Ae. atropalpus lui fournit probablement, lors du développement larvaire, une réserve suffisante de nutriments pour une première ponte en absence de repas de sang. Chez Culex pipiens, les femelles tendent à sélectionner un milieu contenant des bactéries Klebsiella et Aeromonas pour l'oviposition (Diaz-Nieto et al., 2016). D'autres bactéries, comme Bacillus et Staphylococcus, 


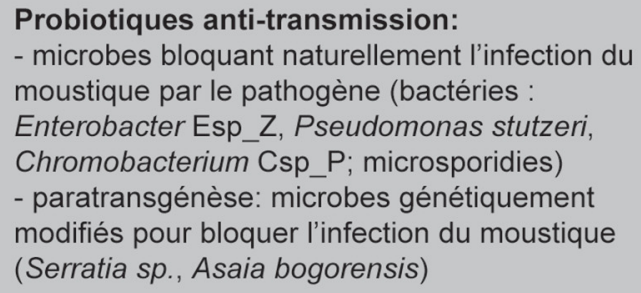

Endosymbiontes:
Bactéries transmises verticalement qui
limitent les populations de vecteurs par
manipulation de la reproduction et/ou
diminuent la longévité du moustique ou
sa compétence vectorielle (Wolbachia,
Spiroplasma)

\section{LUTTE CONTRE LA TRANSMISSION \\ VECTORIELLE \\ Méthodes utilisant des microbes \\ (existantes ou potentielles)}

\begin{abstract}
Insecticides dérivés du microbiote (toxine Cyt produite par Bacillus thuringiensis israelensis, prodigiosine produite par Serratia marcescens)
\end{abstract}

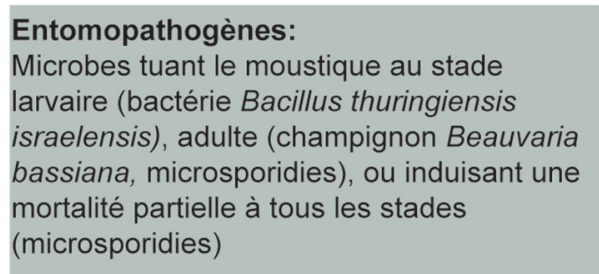

Figure 3. Applications. Probiotiques, prébiotiques, biopesticides, insecticides dérivés du microbiote, endosymbiontes, vaccins, drogues.

sont suspectées d'affecter la fertilité de Culex pipiens mais les mécanismes sous-jacents restent à déterminer (Fouda et al., 2001). Si la présence d'un microbiote joue un rôle positif sur la production d'œufs, la forte multiplication du microbiote suivant le repas de sang peut cependant avoir un effet négatif sur la valeur sélective du moustique. En effet, un traitement antibiotique n'empêchant que partiellement la croissance bactérienne consécutive au repas de sang a pour conséquence une augmentation de la production d'œufs, de la proportion de femelles pondeuses et de la longévité des moustiques (Gendrin et al., 2015). De plus, comme décrit précédemment, la reproduction des moustiques est également affectée par Wolbachia via l'incompatibilité cytoplasmique.

Par ailleurs, certains microbes peuvent également affecter le comportement du moustique. Certaines bactéries environnementales produisent des composants odorants qui peuvent attirer les moustiques, comme les bactéries de la peau chez l'homme. Par exemple, Corynebacterium minutissimum émet des composants volatiles comme l'acide lactique ou le butyl butyrate qui attirent An. gambiae (Verhulst et al., 2010).

Enfin, les bactéries du microbiote semblent participer à la dégradation des molécules insecticides, ce qui a été mis en évidence par un traitement antibiotique dans le cas de la résistance à l'insecticide organophosporé Temephos ${ }^{\circledR}$ chez An. stephensi (Soltani et al., 2017). De même, la charge de Wolbachia chez Culex pipiens est positivement corrélée avec la résistance aux insecticides via les gènes estérases (Berticat et al., 2002).

\section{Applications}

Deux types de stratégies utilisant le microbiote peuvent être envisagés pour lutter contre la transmission vectorielle. D'une part, on peut mettre en place des moyens de «suppression de populations » de moustiques. Cette stratégie à l'avantage de réduire les nuisances en même temps que les risques de transmission vectorielle. Cependant, elle libère une niche écologique et doit donc être poursuivie régulièrement. D'autre part, on peut envisager le «remplacement de populations » de moustiques vecteurs par des moustiques non vecteurs. Cette alternative est plus durable, mais de ce fait les risques associés doivent être étudiés de façon très détaillée. Plusieurs méthodes basées sur ces stratégies sont envisagées et/ou déjà utilisées de façon plus ou moins répandue (Figure 3).

\section{Wolbachia}

Wolbachia est considérée comme un outil de lutte soit par sa capacité à induire de l'incompatibilité cytoplasmique, soit par sa capacité de limiter l'infection virale. Dans le premier cas, des mâles porteurs d'une souche de Wolbachia absente de la population cible, induisant une forte incompatibilité cytoplasmique, sont libérés régulièrement en très grande quantité en vue d'une suppression de population. Dans le cas d'Ae. aegypti notamment, les femelles ne s'accouplent généralement qu'une fois. Si elles s'accouplent avec un mâle porteur de Wolbachia, elles sont donc stérilisées à vie. Cette espèce est naturellement non infectée par Wolbachia mais peut être infectée en laboratoire par des souches de Wolbachia provenant d'autres insectes. La libération de mâles porteurs de Wolbachia induit donc une diminution temporaire de la population de moustiques. Cette stratégie est actuellement utilisée en Californie.

Dans le second cas, des mâles et des femelles porteurs de Wolbachia sont relâchés en très grande quantité, pour que la bactérie colonise la population de moustiques, un 
processus rendu possible par l'incompatibilité cytoplasmique favorisant les femelles infectées au sein de la population. Wolbachia ayant un effet protecteur relativement généraliste sur les arbovirus, la population de moustiques pose ainsi un risque réduit de transmission vectorielle. Cette stratégie de remplacement de population est actuellement utilisée, également sur Ae. Aegypti, dans 12 pays dont l'Australie, le Brésil et la Nouvelle Calédonie.

\section{Paratransgénèse}

Cette méthode est basée sur l'introduction d'un transgène chez un microbe pouvant coloniser le moustique afin d'influencer la survie ou la compétence vectorielle du moustique (Ruang-Areerate \& Kittayapong, 2006). Plusieurs candidats sont actuellement envisagés. Asaia est considérée comme intéressante pour limiter la transmission de Plasmodium par Anopheles (Favia et al., 2007). Un système de paratransgénèse permettant spécifiquement l'expression de transgènes antiplasmodiaux après le repas de sang a notamment été développé chez $A$. bogorensis (Shane et al., 2018). Ces effecteurs exprimés chez An. stephensi inhibent significativement le développement de $P$. berghei. Pantoea agglomerans a également été étudiée dans ce sens et a démontré une certaine efficacité de réduction de l'infection par Plasmodium (Wang et al., 2012). Un critère important dans le choix d'une bactérie paratransgénétique est également l'efficacité de transmission verticale et horizontale. En ce sens, une souche de Serratia a également été proposée, du fait de son efficacité à coloniser rapidement une population de moustiques en cage (Wang et al., 2017). Cependant, des analyses de séquences suggèrent que cette souche appartienne à l'espèce $S$. marcescens, considérée comme un pathogène humain. La paratransgénèse a également été appliquée au champignon entomopathogénique Metharhizium anisopliae pour exprimer le peptide SM1, inhibiteur du développement de Plasmodium chez Anopheles (Fang et al., 2011).

Ces techniques ne sont pas encore mises en place sur le terrain.

\section{Microbes utilisés comme insecticides}

\section{Bactéries}

Certaines souches de bactéries et les métabolites qu'elles produisent peuvent être utilisés comme insecticides naturels. La bactérie Bacillus thuringiensis sérotype israelensis (Bti) produit deux toxines différentes Cry et Cyt (Gonzalez et al., 1982). Les toxines Cry agissent sur un large spectre (Coléoptères, Lépidoptères, Hyménoptères et Diptères) alors que les toxines Cyt agissent spécifiquement sur les Diptères (Schnepf et al., 1998). Ces deux toxines sont activées par le $\mathrm{pH}$ alcalin de l'intestin larvaire et sont capables de dégrader la membrane de l'intestin, causant la mort des larves (Bravo et al., 2007). Bti et ses toxines sont couramment utilisées comme insecticides dans de nombreux pays. Le Firmicute Lysinibacillus sphaericus contient aussi les toxines insecticides Mtx et
Bin qui sont fortement actives sur les larves de moustiques (Berry, 2012). Ces toxines paralysent le système digestif et perturbent le système nerveux. Ces deux classes de larvicides bactériens sont des candidats majeurs, utilisés avec succès sur le terrain pour réduire la population d' $A n$. gambiae en Gambie et au Ghana (Majambere et al., 2007 ; Nartey et al., 2013). Des toxines larvicides de Clostridium bifermentans sérotype Malaysia et la toxine pupicide de Bacillus subtilis sous-espèce subtilis sont aussi des candidats potentiels comme agents biologiques de contrôle de populations de moustiques (Yiallouros et al., 1994; Geetha et al., 2010). Patil et al. ont montré que la prodigiosine, métabolite produit par la bactérie $S$. marcescens, a des effets larvicide et pupicide (Patil et al., 2011 ; Suryawanshi et al., 2015). Chromobacterium réduit la durée de vie des stades immatures et des moustiques adultes, faisant de cette bactérie un autre candidat de lutte antivectorielle (Ramirez et al., 2014). Enfin, des bactéries isolées d'Ae. albopictus montrent in vitro une inhibition d'infection des cellules Vero par le virus de la Crosse, suggérant que ces bactéries sécrètent des métabolites anti-viraux (Joyce et al., 2011).

\section{Champignons}

Metarhizium anisopliae et Beauveria bassiana sont les deux espèces fongiques les plus communément utilisées dans la lutte antivectorielle. Par exemple, l'utilisation de la souche M. anisopliae ICIPE 30 a été suggérée pour lutter contre les vecteurs du paludisme et de la dengue (Scholte et al., 2003, 2007 ; Darbro et al., 2011). Des souches multiples peuvent varier en efficacité chez un moustique hôte. Par exemple, des souches de $B$. bassiana originaires de différents ordres d'insectes varient dans leur virulence sur An. coluzzii (Valero-Jimenez et al., 2014). Récemment, une étude a montré que $B$. bassiana interagissait avec l'intestin du moustique pour accélérer sa mort en induisant une sousexpression des peptides antimicrobiens et de l'enzyme dual oxidase (Wei et al., 2017). Chez Cx quinquefasciatus, la souche m52 de $M$. anisopliae induit un taux élevé de mortalité en deux semaines, soit une semaine plus rapidement que la souche GHA de B. bassiana (Popko et al., 2018).

Chez les microsporodies, $V$. culicis a été considéré comme agent potentiel de contrôle dans la transmission du paludisme. Une étude montre que les femelles An. gambiae infectées par $V$. culicis ont une longévité réduite malgré un impact faible sur la mortalité et la fécondité chez de jeunes femelles (Lorenz \& Koella, 2011). L'utilisation de certaines microsporidies comme E. aedis est envisagée sur $A e$. aegypti. Une étude sur deux ans montre, après contamination avec $E$. aedis, une forte production de larves et d'adultes infectés avec une élimination d'Ae. aegypti dans les 11 semaines suivantes (Becnel \& Johnson, 1999).

\section{Grégarines}

L'utilisation de grégarines dans la lutte biologique contre les moustiques est discutée et demande une connaissance précise de ces parasites et de leurs hôtes. 
On sait notamment que As. culicis est détecté chez les larves d'Ae. aegypti et affecte négativement la population naturelle de moustiques (Sulaiman, 1992). Mais le potentiel des grégarines de lutte biologique chez les moustiques reste à évaluer du fait du manque de données assez significatives sur la physiologie du moustique (Tseng, 2007).

\section{Nématodes}

Les bactéries symbiotiques de nématodes entomopathogènes ont été isolées afin de tester leur pouvoir toxique au niveau larvaire. En effet, les nématodes peuvent tuer les larves par l'intermédiaire de toxines produites par leurs bactéries symbiotiques. Une fois entrée par la bouche, l'anus ou les stigmates de leur hôte, les bactéries symbiotiques sont libérées depuis son intestin dans l'hémocœele de l'insecte (Kaya \& Gaugler, 1993). Elles produisent plusieurs métabolites secondaires qui tuent les insectes par induction de l'immunosuppression et par diffusion dans l'hémolymphe (Park \& Kim, 2000). Par exemple, récemment, chez Steinernema et Heterorhabditis, des bactéries Gram-négatives symbiotiques de nématodes de la famille des Entérobactéries ont été isolées: Xenorhabdus et Photorhabdus respectivement. Une étude montre que la protéine Pir (Photorhabdus insect-related) a une forte toxicité sur les larves d'Ae. aegypti et albopictus (Ahantarig et al., 2009). Des suspensions cellulaires de Photorhabdus luminescens et de Xenorhabdus nematophila sont toxiques par voie orale chez Ae. aegypti (da Silva et al., 2013).

\section{Conclusion}

Les données récentes ont considérablement amélioré la compréhension de la diversité du microbiote du moustique. Elles indiquent que les larves acquièrent leur microbiote à partir de l'environnement, que certains microbes sont transmis de façon trans-stadiale aux adultes et que la composition du microbiote change fortement après un repas sanguin. Avec les techniques de métagénomique, métatranscriptomique, métaprotéomique et métabolomique, la compréhension des mécanismes moléculaires et la signature des relations entre le moustique et son microbiote devraient s'améliorer. En effet, ces approches permettront d'explorer les communautés microbiennes en identifiant les microbes métaboliquement actifs et de découvrir de nouveaux gènes microbiens qui joueraient des rôles importants chez le moustique hôte. Des données supplémentaires permettront de mieux comprendre comment l'environnement du moustique façonne la composition du microbiote, comment les divers microbes influencent la physiologie de leur hôte et l'équilibre de la communauté microbienne.

Les changements climatiques et la mobilité de la population à l'échelle mondiale contribuant grandement à l'expansion des populations de moustiques, les questions d'émergence ou de réémergence de maladies transmises par les moustiques dans le monde se posent. Comme le microbiote du moustique sert d'intermédiaire dans l'adaptation de son hôte aux fluctuations environnementales, mieux connaître le microbiote associé aux moustiques est un aspect très important dans l'élaboration et la mise en place de moyens de lutte contre les maladies à transmission vectorielle.

Remerciements. Nous remercions Jean-Bernard Duchemin pour sa relecture critique du document. Ce travail est financé par Le Programme Investissement d'Avenir du Laboratoire d'Excellence «Integrative Biology of Emerging Infectious Diseases» (financement numéro ANR-10-LABX-62-IBEID) et par l'Institut Pasteur.

\section{Références}

Ahantarig, A., Chantawat, N., Waterfield, N.R., ffrenchConstant, R., Kittayapong, P. (2009). PirAB toxin from Photorhabdus asymbiotica as a larvicide against dengue vectors. Appl Environ Microbiol, 75, 4627-4629.

Akorli, J., Gendrin, M., Pels, N.A., Yeboah-Manu, D., Christophides, G.K., Wilson, M.D. (2016). Seasonality and locality affect the diversity of Anopheles gambiae and Anopheles coluzzii midgut microbiota from Ghana. PloS one, 11, e0157529.

Andreadis, T.G. (2007). Microsporidian parasites of mosquitoes. J Am Mosq Control Assoc, 23, 3-29.

Ang'Ang'O, L.M. (2018). Molecular characterisation of microsporidia $\mathrm{mb}$ species and correlation with plasmodium presence in anopheles mosquitoes in Mwea and Mbita, Rapport de Master, University of Nairobi, Kenya, Available from http://erepository.uonbi.ac.ke/handle/11295/104416.

Anglero-Rodriguez, Y.I., Blumberg, B.J., Dong, Y., Sandiford, S.L., Pike, A., Clayton, A.M., Dimopoulos, G. (2016). A natural Anopheles-associated Penicillium chrysogenum enhances mosquito susceptibility to Plasmodium infection. Sci Rep, 6, 34084.

Anglero-Rodriguez, Y.I., Talyuli, O.A., Blumberg, B.J., Kang, S., Demby, C., Shields, A., Carlson, J., Jupatanakul, N., Dimopoulos, G. (2017). An Aedes aegypti-associated fungus increases susceptibility to dengue virus by modulating gut trypsin activity. Elife, 6, e28844.

Astudillo-Garcia, C., Bell, J.J., Webster, N.S., Glasl, B., Jompa, J., Montoya, J.M., Taylor, M.W. (2017). Evaluating the core microbiota in complex communities: A systematic investigation. Environ Microbiol, 19, 1450-1462.

Baldini, F., Segata, N., Pompon, J., Marcenac, P., Shaw, W.R., Dabire, R.K., Diabate, A., Levashina, E.A., Catteruccia, F. (2014). Evidence of natural Wolbachia infections in field populations of Anopheles gambiae. Nat Commun, 5, 3985.

Bando, H., Okado, K., Guelbeogo, W.M., Badolo, A., Aonuma, H., Nelson, B., Fukumoto, S., Xuan, X., Sagnon, N., Kanuka, H. (2013). Intra-specific diversity of Serratia marcescens in Anopheles mosquito midgut defines Plasmodium transmission capacity. Sci Rep, 3, 1641.

Barnard, D.R., Xue, R.D., Rotstein, M.A., Becnel, J.J. (2007). Microsporidiosis (Microsporidia: Culicosporidae) alters blood-feeding responses and DEET repellency in Aedes aegypti (Diptera: Culicidae). J Med Entomol, 44, 1040-1046.

Becker, N., Petric, D., Zgomba, M., Boase, C., Madon, M., Dahl, C., Kaiser, A., Mosquitoes and their control, 2nd Edition, Springer, 2010.

Becnel, J.J., Johnson, M.A. (1999). Impact of Edhazardia aedi (Microsporidia: Culicosporidae) on a seminatural population of Aedes aegypti (Diptera: Culicidae). Biol Control, 18, 39-48. 
Beier, J.C., Harris, C. (1983). Ascogregarina barretti (Sporozoa: diplocystidae) infections in natural populations of Aedes triseriatus (Diptera: Culicidae). J Parasitol, 69, 430-431.

Beier, J.C., Chadee, D.D., Charran, A., Comiskey, N.M., Wesson, D.M. (1995). Country-wide prevalence of Ascogregarina culicis (apicomplexa: lecudinidae), a protozoan parasite of Aedes aegypti in Trinidad, West Indies. J Am Mosq Control Assoc, 11, 419-423.

Belda, E., Coulibaly, B., Fofana, A., Beavogui, A.H., Traore, S. F., Gohl, D.M., Vernick, K.D., Riehle, M.M. (2017). Preferential suppression of Anopheles gambiae host sequences allows detection of the mosquito eukaryotic microbiome. Sci Rep, 7, 3241 .

Benoit, J.B., Lopez-Martinez, G., Patrick, K.R., Phillips, Z.P., Krause, T.B., Denlinger, D.L. (2011). Drinking a hot blood meal elicits a protective heat shock response in mosquitoes. Proc Natl Acad Sci USA, 108, 8026-8029.

Berry, C. (2012). The bacterium, Lysinibacillus sphaericus, as an insect pathogen. J Invertebr Pathol, 109, 1-10.

Berticat, C., Rousset, F., Raymond, M., Berthomieu, A., Weill, M. (2002). High Wolbachia density in insecticide-resistant mosquitoes. Proc Biol Sci, 269, 1413-1416.

Boissière, A., Tchioffo, M.T., Bachar, D., Abate, L., Marie, A., Nsango, S.E., Shahbazkia, H.R., Awono-Ambene, P.H., Levashina, E.A., Christen, R., Morlais, I. (2012). Midgut microbiota of the malaria mosquito vector Anopheles gambiae and interactions with Plasmodium falciparum infection. PLoS Pathog, 8, e1002742.

Bolling, B.G., Olea-Popelka, F.J., Eisen, L., Moore, C.G., Blair, C.D. (2012). Transmission dynamics of an insect-specific flavivirus in a naturally infected Culex pipiens laboratory colony and effects of co-infection on vector competence for West Nile virus. Virology, 427, 90-97.

Bolling, B.G., Weaver, S.C., Tesh, R.B., Vasilakis, N. (2015). Insect-specific virus discovery: Significance for the Arbovirus community. Viruses, 7, 4911-4928.

Borucki, M.K., Kempf, B.J., Blitvich, B.J., Blair, C.D., Beaty, B. J. (2002). La Crosse virus: Replication in vertebrate and invertebrate hosts. Microbes Infect, 4, 341-350.

Bozic, J., Capone, A., Pediconi, D., Mensah, P., Cappelli, A., Valzano, M., Mancini, M.V., Scuppa, P., Martin, E., Epis, S., Rossi, P., Favia, G., Ricci, I. (2017). Mosquitoes can harbour yeasts of clinical significance and contribute to their environmental dissemination. Environ Microbiol Rep, 9, 642-648.

Bravo, A., Gill, S.S., Soberon, M. (2007). Mode of action of Bacillus thuringiensis Cry and Cyt toxins and their potential for insect control. Toxicon, 49, 423-435.

Burki, T. (2018). Increase of West Nile virus cases in Europe for 2018. Lancet, 392(10152), 1000.

Burt, F.J., Chen, W., Miner, J.J., Lenschow, D.J., Merits, A., Schnettler, E., Kohl, A., Rudd, P.A., Taylor, A., Herrero, L. J., Zaid, A., Ng, L.F.P., Mahalingam, S. (2017). Chikungunya virus: An update on the biology and pathogenesis of this emerging pathogen. Lancet Infect Dis, 17, e107-e117.

Campbell, C.L., Mummey, D.L., Schmidtmann, E.T., Wilson, W.C. (2004). Culture-independent analysis of midgut microbiota in the arbovirus vector Culicoides sonorensis (Diptera: Ceratopogonidae). J Med Entomol, 41, 340-348.

Caragata, E.P., Rances, E., Hedges, L.M., Gofton, A.W., Johnson, K.N., O’Neill, S.L., McGraw, E.A. (2013). Dietary cholesterol modulates pathogen blocking by Wolbachia. PLoS Pathog, 9, e1003459.

Caragata, E.P., Rances, E., O’Neill, S.L., McGraw, E.A. (2014). Competition for amino acids between Wolbachia and the mosquito host, Aedes aegypti. Microb Ecol, 67, 205-218.
Chandler, J.A., Liu, R.M., Bennett, S.N. (2015). RNA shotgun metagenomic sequencing of northern California (USA) mosquitoes uncovers viruses, bacteria, and fungi. Front Microbiol, 6, 185.

Chao, J., Wistreich, G.A., Moore, J. (1963). Failure to isolate microorganisms from within mosquito eggs. Ann Entomol Soc Am, 56, 559-561.

Chavshin, A.R., Oshaghi, M.A., Vatandoost, H., Yakhchali, B., Zarenejad, F., Terenius, O. (2015). Malpighian tubules are important determinants of Pseudomonas transstadial transmission and longtime persistence in Anopheles stephensi. Parasit Vectors, 8, 36.

Chepkemoi, S.T., Mararo, E., Butungi, H., Paredes, J., Masiga, D., Sinkins, S.P., Herren, J.K. (2017). Identification of Spiroplasmainsolitum symbionts in Anopheles gambiae. Wellcome Open Res, 2, 90.

Chouaia, B., Rossi, P., Epis, S., Mosca, M., Ricci, I., Damiani, C., Ulissi, U., Crotti, E., Daffonchio, D., Bandi, C., Favia, G. (2012). Delayed larval development in Anopheles mosquitoes deprived of Asaia bacterial symbionts. BMC Microbiol, 12 (Suppl 1), S2.

Cirimotich, C.M., Dong, Y., Clayton, A.M., Sandiford, S.L., Souza-Neto, J.A., Mulenga, M., Dimopoulos, G. (2011). Natural microbe-mediated refractoriness to Plasmodium infection in Anopheles gambiae. Science, 332, 855-858.

Clements, A.N., The biology of mosquitoes: Development, nutrition, and reproduction. Chapman \& Hall, London, 1992.

Cleton, N., Koopmans, M., Reimerink, J., Godeke, G.J., Reusken, C. (2012). Come fly with me: Review of clinically important arboviruses for global travelers. J Clin Virol, 55, 191-203.

Coon, K.L., Vogel, K.J., Brown, M.R., Strand, M.R. (2014). Mosquitoes rely on their gut microbiota for development. Mol Ecol, 23, 2727-2739.

Coon, K.L., Brown, M.R., Strand, M.R. (2016a). Gut bacteria differentially affect egg production in the anautogenous mosquito Aedes aegypti and facultatively autogenous mosquito Aedes atropalpus (Diptera: Culicidae). Parasit Vectors, 9, 375 .

Coon, K.L., Brown, M.R., Strand, M.R. (2016b). Mosquitoes host communities of bacteria that are essential for development but vary greatly between local habitats. Mol Ecol, 25, 5806-5826.

Coon, K.L., Valzania, L., McKinney, D.A., Vogel, K.J., Brown, M.R., Strand, M.R. (2017). Bacteria-mediated hypoxia functions as a signal for mosquito development. Proc Natl Acad Sci USA, 114, E5362-E5369.

Correa, M.A., Matusovsky, B., Brackney, D.E., Steven, B. (2018). Generation of axenic Aedes aegypti demonstrate live bacteria are not required for mosquito development. Nat Commun, 9, 4464.

Crotti, E., Rizzi, A., Chouaia, B., Ricci, I., Favia, G., Alma, A., Sacchi, L., Bourtzis, K., Mandrioli, M., Cherif, A., Bandi, C., Daffonchio, D. (2010). Acetic acid bacteria, newly emerging symbionts of insects. Appl Environ Microbiol, 76, 6963-6970.

da Silva, O.S., Prado, G.R., da Silva, J.L., Silva, C.E., da Costa, M., Heermann, R. (2013). Oral toxicity of Photorhabdus luminescens and Xenorhabdus nematophila (Enterobacteriaceae) against Aedes aegypti (Diptera: Culicidae). Parasitol Res, 112, 2891-2896.

Darbro, J.M., Graham, R.I., Kay, B.H., Ryan, P.A., Thomas, M. B. (2011). Evaluation of entomopathogenic fungi as potentiel biological control agents of the dengue mosquito, Aedes aegypti (Diptera: Culicidae). Biocontrol Sci Technol, 21, 1027-1047. 
David, M.R., Santos, L.M., Vicente, A.C., Maciel-de-Freitas, R. (2016). Effects of environment, dietary regime and ageing on the dengue vector microbiota: Evidence of a core microbiota throughout Aedes aegypti lifespan. Mem Inst Oswaldo Cruz, $111,577-587$.

Diaz-Nieto, L.M., D’Alessio, C., Perotti, M.A., Beron, C.M. (2016). Culex pipiens development is greatly influenced by native bacteria and exogenous yeast. PloS One, 11, e0153133.

Dickson, L.B., Jiolle, D., Minard, G., Moltini-Conclois, I., Volant, S., Ghozlane, A., Bouchier, C., Ayala, D., Paupy, C., Moro, C.V., Lambrechts, L. (2017). Carryover effects of larval exposure to different environmental bacteria drive adult trait variation in a mosquito vector. Sci Adv, 3, e1700585.

Dobson, S.L., Bourtzis, K., Braig, H.R., Jones, B.F., Zhou, W., Rousset, F., O'Neill, S.L. (1999). Wolbachia infections are distributed throughout insect somatic and germ line tissues. Insect Biochem Mol Biol, 29, 153-160.

Dong, Y., Manfredini, F., Dimopoulos, G. (2009). Implication of the mosquito midgut microbiota in the defense against malaria parasites. PLoS Pathog, 5, e1000423.

Douglas, A.E. (2009). The microbial dimension in insect nutritional ecology. Funct Ecol, 23, 38-47.

Duguma, D., Hall, M.W., Rugman-Jones, P., Stouthamer, R., Terenius, O., Neufeld, J.D., Walton, W.E. (2015). Developmental succession of the microbiome of Culex mosquitoes. BMC Microbiol, 15, 140.

Esteva, L., Rivas, G., Yang, H.M. (2006). Modelling parasitism and predation of mosquitoes by water mites. J Math Biol, 53, 540-555.

Fang, W., Vega-Rodriguez, J., Ghosh, A.K., Jacobs-Lorena, M., Kang, A., St Leger, R.J. (2011). Development of transgenic fungi that kill human malaria parasites in mosquitoes. Science, 331, 1074-1077.

Farenhorst, M., Knols, B.G.J. (2007). Fungal entomopathogens for the control of adult mosquitoes: A look at the issues. Proc Neth Entomol Soc Meet, 18.

Favia, G., Ricci, I., Damiani, C., Raddadi, N., Crotti, E., Marzorati, M., Rizzi, A., Urso, R., Brusetti, L., Borin, S., Mora, D., Scuppa, P., Pasqualini, L., Clementi, E., Genchi, M., Corona, S., Negri, I., Grandi, G., Alma, A., Kramer, L., Esposito, F., Bandi, C., Sacchi, L., Daffonchio, D. (2007). Bacteria of the genus Asaia stably associate with Anopheles stephensi, an Asian malarial mosquito vector. Proc Natl Acad Sci USA, 104, 9047-9051.

Foster, W.A. (1995). Mosquito sugar feeding and reproductive energetics. Annu Rev Entomol, 40, 443-474.

Fouda, M.A., Hassan, M.I., Al-Daly, A.G., Hammad, K.M. (2001). Effect of midgut bacteria of Culex pipiens L. on digestion and reproduction. J Egypt Soc Parasitol, 31, 767780 .

Gaibani, P., Rossini, G. (2017). An overview of Usutu virus. Microbes Infect, 19, 382-387.

Gaio Ade, O., Gusmao, D.S., Santos, A.V., Berbert-Molina, M. A., Pimenta, P.F., Lemos, F.J. (2011). Contribution of midgut bacteria to blood digestion and egg production in Aedes aegypti (Diptera: Culicidae) (L.). Parasit Vectors, 4, 105.

Garcia, J.J., Fukuda, T., Becnel, J.J. (1994). Seasonality, prevalence and pathogenicity of the gregarine Ascogregarina taiwanensis (Apicomplexa: Lecudinidae) in mosquitoes from Florida. J Am Mosq Control Assoc, 10, 413-418.

Geetha, I., Manonmani, A.M., Paily, K.P. (2010). Identification and characterization of a mosquito pupicidal metabolite of a Bacillus subtilis subsp. subtilis strain. Appl Microbiol Biotechnol, 86, 1737-1744.
Gendrin, M., Christophides, G.K. (2013). The Anopheles mosquito microbiota and their impact on pathogen transmission, In: Anopheles mosquitoes, New insights into malaria vectors, Intech Open, pp. 525-548, DOI:10.5772/55107.

Gendrin, M., Rodgers, F.H., Yerbanga, R.S., Ouedraogo, J.B., Basanez, M.G., Cohuet, A., Christophides, G.K. (2015). Antibiotics in ingested human blood affect the mosquito microbiota and capacity to transmit malaria. Nat Commun, 6,5921 .

Gimonneau, G., Tchioffo, M.T., Abate, L., Boissière, A., AwonoAmbene, P.H., Nsango, S.E., Christen, R., Morlais, I. (2014). Composition of Anopheles coluzzii and Anopheles gambiae microbiota from larval to adult stages. Infect Genet Evol, 28, 715-724

Glaser, R.L., Meola, M.A. (2010). The native Wolbachia endosymbionts of Drosophila melanogaster and Culex quinquefasciatus increase host resistance to West Nile virus infection. PloS One, 5, e11977.

Goenaga, S., Kenney, J.L., Duggal, N.K., Delorey, M., Ebel, G. D., Zhang, B., Levis, S.C., Enria, D.A., Brault, A.C. (2015). Potential for co-infection of a mosquito-specific Flavivirus, Nhumirim virus, to block West Nile virus transmission in mosquitoes. Viruses, 7, 5801-5812.

Gomes, F.M., Hixson, B.L., Tyner, M.D.W., Ramirez, J.L., Canepa, G.E., Alves, E.S.T.L., Molina-Cruz, A., Keita, M., Kane, F., Traore, B., Sogoba, N., Barillas-Mury, C. (2017). Effect of naturally occurring Wolbachia in Anopheles gambiae s.l. mosquitoes from Mali on Plasmodium falciparum malaria transmission. Proc Natl Acad Sci USA, 114, 12566-12571.

Gonzalez, J.M., Jr., Brown, B.J., Carlton, B.C. (1982). Transfer of Bacillus thuringiensis plasmids coding for delta-endotoxin among strains of B. thuringiensis and B. cereus. Proc Natl Acad Sci USA, 79, 6951-6955.

Gusmao, D.S., Santos, A.V., Marini, D.C., Russo Ede, S., Peixoto, A.M., Bacci Junior, M., Berbert-Molina, M.A., Lemos, F.J. (2007). First isolation of microorganisms from the gut diverticulum of Aedes aegypti (Diptera: Culicidae): New perspectives for an insect-bacteria association. Mem Inst Oswaldo Cruz, 102, 919-924.

Gusmao, D.S., Santos, A.V., Marini, D.C., Bacci, M., Jr., Berbert-Molina, M.A., Lemos, F.J. (2010). Culture-dependent and culture-independent characterization of microorganisms associated with Aedes aegypti (Diptera: Culicidae) (L.) and dynamics of bacterial colonization in the midgut. Acta Trop, 115, 275-281.

Guzman, M.G., Harris, E. (2015). Dengue. Lancet, 385, 453-465.

Haddow, A.D., Guzman, H., Popov, V.L., Wood, T.G., Widen, S.G., Haddow, A.D., Tesh, R.B., Weaver, S.C. (2013). First isolation of Aedes flavivirus in the western hemisphere and evidence of vertical transmission in the mosquito Aedes (Stegomyia) albopictus (Diptera: Culicidae). Virology, 440, 134-139.

Halbach, R., Junglen, S., van Rij, R.P. (2017). Mosquito-specific and mosquito-borne viruses: Evolution, infection, and host defense. Curr Opin Insect Sci, 22, 16-27.

Haselkorn, T.S., Markow, T.A., Moran, N.A. (2009). Multiple introductions of the Spiroplasma bacterial endosymbiont into Drosophila. Mol Ecol, 18, 1294-1305.

Hegde, S., Khanipov, K., Albayrak, L., Golovko, G., Pimenova, M., Saldana, M.A., Rojas, M.M., Hornett, E.A., Motl, G.C., Fredregill, C.L., Dennett, J.A., Debboun, M., Fofanov, Y., Hughes, G.L. (2018). Microbiome interaction networks and community structure from laboratory-reared and fieldcollected Aedes aegypti, Aedes albopictus, and Culex quinquefasciatus mosquito vectors. Front Microbiol, 9, 2160. 
Hermanns, K., Zirkel, F., Kopp, A., Marklewitz, M., Rwego, I.B. Estrada, A., Gillespie, T.R., Drosten, C., Junglen, S. (2017). Discovery of a novel alphavirus related to Eilat virus. J Gen Virol, 98, 43-49.

Herren, J.K., Paredes, J.C., Schupfer, F., Lemaitre, B. (2013). Vertical transmission of a Drosophila endosymbiont via cooption of the yolk transport and internalization machinery. MBio, 4(2), e00532-12.

Hughes, G.L., Dodson, B.L., Johnson, R.M., Murdock, C.C., Tsujimoto, H., Suzuki, Y., Patt, A.A., Cui, L., Nossa, C.W., Barry, R.M., Sakamoto, J.M., Hornett, E.A., Rasgon, J.L. (2014). Native microbiome impedes vertical transmission of Wolbachia in Anopheles mosquitoes. Proc Natl Acad Sci USA, 111, 12498-12503.

Joyce, J.D., Nogueira, J.R., Bales, A.A., Pittman, K.E., Anderson, J.R. (2011). Interactions between La Crosse virus and bacteria isolated from the digestive tract of Aedes albopictus (Diptera: Culicidae). J Med Entomol, 48, 389-394.

Jupatanakul, N., Sim, S., Dimopoulos, G. (2014). The insect microbiome modulates vector competence for arboviruses. Viruses, 6, 4294-4313.

Kajimura, H., Hijii, N. (1992). Dynamics of the fungal symbionts in the gallery system and the mycangia of the ambrosia beetle, Xylosandrus mutilatus (Blandford) (Coleoptera, Scolytidae) in relation to its life-history. Ecol Res, 7, 107-117.

Kaya, H.K., Gaugler, R. (1993). Entomopathogenic nematodes. Annu Rev Entomol, 38, 181-206.

Kenney, J.L., Solberg, O.D., Langevin, S.A., Brault, A.C. (2014). Characterization of a novel insect-specific flavivirus from Brazil: potential for inhibition of infection of arthropod cells with medically important flaviviruses. J Gen Virol, 95, 2796-2808.

Koella, J.C., Agnew, P. (1997). Blood-feeding success of the mosquito Aedes aegypti depends on the transmission route of its parasite Edhazardia aedis. Oikos, 78, 311-316.

Kumar, S., Molina-Cruz, A., Gupta, L., Rodrigues, J., BarillasMury, C. (2010). A peroxidase/dual oxidase system modulates midgut epithelial immunity in Anopheles gambiae. Science, 327, 1644-1648.

Kuwata, R., Isawa, H., Hoshino, K., Sasaki, T., Kobayashi, M., Maeda, K., Sawabe, K. (2015). Analysis of mosquito-borne flavivirus superinfection in Culex tritaeniorhynchus (Diptera: Culicidae) cells persistently infected with Culex Flavivirus (Flaviviridae). J Med Entomol, 52, 222-229.

Lantova, L., Volf, P. (2014). Mosquito and sand fly gregarines of the genus Ascogregarina and Psychodiella (Apicomplexa: Eugregarinorida, Aseptatorina)-overview of their taxonomy, life cycle, host specificity and pathogenicity. Infect Genet Evol, 28, 616-627.

Lindh, J.M., Borg-Karlson, A.K., Faye, I. (2008). Transstadial and horizontal transfer of bacteria within a colony of Anopheles gambiae (Diptera: Culicidae) and oviposition response to bacteria-containing water. Acta Trop, 107, 242250.

Liu, H., Li, M.H., Zhai, Y.G., Meng, W.S., Sun, X.H., Cao, Y.X., Fu, S.H., Wang, H.Y., Xu, L.H., Tang, Q., Liang, G.D. (2010). Banna virus, China, 1987-2007. Emerg Infect Dis, 16, 514-517.

Lorenz, L.M., Koella, J.C. (2011). The microsporidian parasite Vavraia culicis as a potential late life-acting control agent of malaria. Evol Appl, 4, 783-790.

Majambere, S., Lindsay, S.W., Green, C., Kandeh, B., Fillinger, U. (2007). Microbial larvicides for malaria control in the Gambia. Malar J, 6, 76 .

Mancini, M.V., Damiani, C., Accoti, A., Tallarita, M., Nunzi, E., Cappelli, A., Bozic, J., Catanzani, R., Rossi, P., Valzano, M., Serrao, A., Ricci, I., Spaccapelo, R., Favia, G. (2018).
Estimating bacteria diversity in different organs of nine species of mosquito by next generation sequencing. $B M C$ Microbiol, 18, 126.

Manguin, S., Bangs, M.J., Pothikasikorn, J., Chareonviriyaphap, T. (2010). Review on global co-transmission of human Plasmodium species and Wuchereria bancrofti by Anopheles mosquitoes. Infect Genet Evol, 10, 159-177.

Marklewitz, M., Junglen, S. (2018). Evolutionary and ecological insights into the emergence of arthropod-borne viruses. Acta Trop, 190, 52-58.

McCray, E.M., Jr., Fay, R.W., Schoof, H.F. (1970). The bionomics of Lankesteria culicis and Aedes aegypti. J Invertebr Pathol, 16, 42-53.

McMillen, C.M., Hartman, A.L. (2018). Rift Valley fever in animals and humans: Current perspectives. Antiviral Res, 156, 29-37.

Meister, S., Agianian, B., Turlure, F., Relogio, A., Morlais, I., Kafatos, F.C., Christophides, G.K. (2009). Anopheles gambiae PGRPLC-mediated defense against bacteria modulates infections with malaria parasites. PLoS Pathog, 5, e1000542.

Minard, G., Tran, F.H., Raharimalala, F.N., Hellard, E., Ravelonandro, P., Mavingui, P., Valiente Moro, C. (2013). Prevalence, genomic and metabolic profiles of Acinetobacter and Asaia associated with field-caught Aedes albopictus from Madagascar. FEMS Microbiol Ecol, 83, 63-73.

Moll, R.M., Romoser, W.S., Modrzakowski, M.C., Moncayo, A. C., Lerdthusnee, K. (2001). Meconial peritrophic membranes and the fate of midgut bacteria during mosquito (Diptera: Culicidae) metamorphosis. J Med Entomol, 38, 29-32.

Monath, T.P., Vasconcelos, P.F. (2015). Yellow fever. J Clin Virol, 64, 160-173.

Moran, N.A., Jarvik, T. (2010). Lateral transfer of genes from fungi underlies carotenoid production in aphids. Science, 328 , 624-627.

Mourya, D.T., Singh, D.K., Yadav, P., Gokhale, M.D., Barde, P. V., Narayan, N.B., Thakare, J.P., Mishra, A.C., Shouche, Y. S. (2003). Role of gregarine parasite Ascogregarina culicis (Apicomplexa: Lecudinidae) in the maintenance of Chikungunya virus in vector mosquito. J Eukaryot Microbiol, 50, 379-382.

Mousson, L., Zouache, K., Arias-Goeta, C., Raquin, V., Mavingui, P., Failloux, A.B. (2012). The native Wolbachia symbionts limit transmission of dengue virus in Aedes albopictus. PLoS Negl Trop Dis, 6, e1989.

Munstermann, L.E., Wesson, D.M. (1990). First record of Ascogregarina taiwanensis (Apicomplexa: Lecudinidae) in North American Aedes albopictus. J Am Mosqu Control Assoc, 6, 235-243.

Musso, D., Gubler, D.J. (2016). Zika Virus. Clin Microbiol Rev, $29,487-524$.

Muturi, E.J., Bara, J.J., Rooney, A.P., Hansen, A.K. (2016). Midgut fungal and bacterial microbiota of Aedes triseriatus and Aedes japonicus shift in response to La Crosse virus infection. Mol Ecol, 25, 4075-4090.

Nartey, R., Owusu-Dabo, E., Kruppa, T., Baffour-Awuah, S., Annan, A., Oppong, S., Becker, N., Obiri-Danso, K. (2013). Use of Bacillus thuringiensis var israelensis as a viable option in an Integrated Malaria Vector Control Programme in the Kumasi Metropolis, Ghana, Parasit Vectors, 6.

Nasar, F., Palacios, G., Gorchakov, R.V., Guzman, H., Da Rosa, A.P., Savji, N., Popov, V.L., Sherman, M.B., Lipkin, W.I., Tesh, R.B., Weaver, S.C. (2012). Eilat virus, a unique alphavirus with host range restricted to insects by RNA replication. Proc Natl Acad Sci USA, 109, 14622-14627.

Nation, J.L., Insect physiology and biochemistry, 3rd Edition, CRC Press, Boca Raton, 2016. 
Oliveira, J.H., Goncalves, R.L., Lara, F.A., Dias, F.A., Gandara, A.C., Menna-Barreto, R.F., Edwards, M.C., Laurindo, F.R., Silva-Neto, M.A., Sorgine, M.H., Oliveira, P.L. (2011). Blood meal-derived heme decreases ROS levels in the midgut of Aedes aegypti and allows proliferation of intestinal microbiota. PLoS Pathog, 7, e1001320.

Osei-Poku, J., Mbogo, C.M., Palmer, W.J., Jiggins, F.M. (2012). Deep sequencing reveals extensive variation in the gut microbiota of wild mosquitoes from Kenya. Mol Ecol, 21, 5138-5150.

Pan, X., Zhou, G., Wu, J., Bian, G., Lu, P., Raikhel, A.S., Xi, Z. (2012). Wolbachia induces reactive oxygen species (ROS)dependent activation of the Toll pathway to control dengue virus in the mosquito Aedes aegypti. Proc Natl Acad Sci USA, 109, E23-31.

Park, Y., Kim, Y. (2000). Eicosanoids rescue Spodoptera exigua infected with Xenorhabdus nematophilus, the symbiotic bacteria to the entomopathogenic nematode Steinernema carpocapsae. J Insect Physiol, 46, 1469-1476.

Patil, C.D., Patil, S.V., Salunke, B.K., Salunkhe, R.B. (2011). Prodigiosin produced by Serratia marcescens NMCC46 as a mosquito larvicidal agent against Aedes aegypti and Anopheles stephensi. Parasitol Res, 109, 1179-1187.

Patterson, J., Sammon, M., Garg, M. (2016). Dengue, Zika and Chikungunya: Emerging arboviruses in the new world. West $J$ Emerg Med, 17, 671-679.

Platzer, E.G. (2007). Mermithid nematodes. J Am Mosq Control Assoc, 23, 58-64.

Ponnusamy, L., Boroczky, K., Wesson, D.M., Schal, C., Apperson, C.S. (2011). Bacteria stimulate hatching of yellow fever mosquito eggs. PloS one, 6, e24409.

Popko, D.A., Henke, J.A., Mullens, B.A., Walton, W.E. (2018). Evaluation of two entomopathogenic fungi for control of Culex quinquefasciatus (Diptera: Culicidae) in underground storm drains in the Coachella Valley, California, United States, J Med Entomol, 55, 654-665.

Pumpuni, C.B., Beier, M.S., Nataro, J.P., Guers, L.D., Davis, J. R. (1993). Plasmodium falciparum: Inhibition of sporogonic development in Anopheles stephensi by Gram-negative bacteria. Exp Parasitol, 77, 195-199.

Ramirez, J.L., Souza-Neto, J., Torres Cosme, R., Rovira, J., Ortiz, A., Pascale, J.M., Dimopoulos, G. (2012). Reciprocal tripartite interactions between the Aedes aegypti midgut microbiota, innate immune system and dengue virus influences vector competence. PLoS Negl Trop Dis, 6, e1561.

Ramirez, J.L., Short, S.M., Bahia, A.C., Saraiva, R.G., Dong, Y., Kang, S., Tripathi, A., Mlambo, G., Dimopoulos, G. (2014). Chromobacterium Csp P reduces malaria and dengue infection in vector mosquitoes and has entomopathogenic and in vitro anti-pathogen activities. PLoS Pathog, 10, e1004398.

Ramirez, J.L., Barletta, A.B.F., Barillas-Mury, C.V., Molecular mechanisms mediating immune priming in Anopheles gambiae mosquitoes, In: Arthropod vector: Controller of disease transmission, Volume 1, Academic Press, 2017, pp. 91-100.

Ranger, C.M., Biedermann, P.H.W., Phuntumart, V., Beligala, G.U., Ghosh, S., Palmquist, D.E., Mueller, R., Barnett, J., Schultz, P.B., Reding, M.E., Benz, J.P. (2018). Symbiont selection via alcohol benefits fungus farming by ambrosia beetles. Proc Natl Acad Sci USA, 115, 4447-4452.

Rani, A., Sharma, A., Rajagopal, R., Adak, T., Bhatnagar, R. K. (2009). Bacterial diversity analysis of larvae and adult midgut microflora using culture-dependent and cultureindependent methods in lab-reared and field-collected Anopheles stephensi-an Asian malarial vector. $B M C$ Microbiol, 9, 96.
Reeves, W.K. (2004). Oviposition by Aedes aegypti (Diptera: Culicidae) in relation to conspecific larvae infected with internal symbiotes. $J$ Vector Ecol, 29, 159-163.

Reyes-Villanueva, F., Becnel, J.J., Butler, J.F. (2003). Susceptibility of Aedes aegypti and Aedes albopictus larvae to Ascogregarina culicis and Ascogregarina taiwanensis (Apicomplexa: Lecudinidae) from Florida. J Invertebr Pathol, 84, 47-53.

Rezza, G., Chen, R., Weaver, S.C. (2017). O'nyong-nyong fever: A neglected mosquito-borne viral disease. Pathog Glob Health, 111, 271-275.

Rodgers, F.H., Gendrin, M., Wyer, C.A.S., Christophides, G.K. (2017). Microbiota-induced peritrophic matrix regulates midgut homeostasis and prevents systemic infection of malaria vector mosquitoes. PLoS Pathog, 13, e1006391.

Romo, H., Kenney, J.L., Blitvich, B.J., Brault, A.C. (2018). Restriction of Zika virus infection and transmission in Aedes aegypti mediated by an insect-specific flavivirus. Emerg Microbes Infect, 7, 181.

Romoli, O., Gendrin, M. (2018). The tripartite interactions between the mosquito, its microbiota and Plasmodium. Parasit Vectors, 11, 200.

Roossinck, M.J., Martin, D.P., Roumagnac, P. (2015). Plant virus metagenomics: Advances in virus discovery. Phytopathology, 105, 716-727.

Rossi, P., Ricci, I., Cappelli, A., Damiani, C., Ulissi, U., Mancini, M.V., Valzano, M., Capone, A., Epis, S., Crotti, E., Chouaia, B., Scuppa, P., Joshi, D., Xi, Z., Mandrioli, M., Sacchi, L., O'Neill, S.L., Favia, G. (2015). Mutual exclusion of Asaia and Wolbachia in the reproductive organs of mosquito vectors. Parasit Vectors, 8, 278.

Roundy, C.M., Azar, S.R., Rossi, S.L., Weaver, S.C., Vasilakis, N. (2017). Insect-specific viruses: A historical overview and recent developments. Adv Virus Res, 98, 119-146.

Rozemoon, L.E. (1935). The relation of bacteria and bacterial filtrates to the development of mosquito larvae. Am J Hyg, 21, 167-179.

Ruang-Areerate, T., Kittayapong, P. (2006). Wolbachia transinfection in Aedes aegypti: A potential gene driver of dengue vectors. Proc Natl Acad Sci USA, 103, 12534-12539.

Saiyasombat, R., Bolling, B.G., Brault, A.C., Bartholomay, L. C., Blitvich, B.J. (2011). Evidence of efficient transovarial transmission of Culex flavivirus by Culex pipiens (Diptera: Culicidae). J Med Entomol, 48, 1031-1038.

Schnepf, E., Crickmore, N., Van Rie, J., Lereclus, D., Baum, J., Feitelson, J., Zeigler, D.R., Dean, D.H. (1998). Bacillus thuringiensis and its pesticidal crystal proteins. Microbiol Mol Biol Rev, 62, 775-806.

Scholte, E.J., Njiru, B.N., Smallegange, R.C., Takken, W., Knols, B.G. (2003). Infection of malaria (Anopheles gambiae s.s.) and filariasis (Culex quinquefasciatus) vectors with the entomopathogenic fungus Metarhizium anisopliae mopathogenic fungi for mosquito control: A review. J Insect Sci, 4, 19.

Scholte, E.J., Knols, B.G., Samson, R.A., Tzakken, W. (2004). Entomologic fungi for mosquito control. A review. J Insect Sci, 4, 19.

Scholte, E.J., Takken, W., Knols, B.G. (2007). Infection of adult Aedes aegypti and Ae. albopictus mosquitoes with the entomopathogenic fungus Metarhizium anisopliae. Acta Trop, 102, 151-158.

Segata, N., Baldini, F., Pompon, J., Garrett, W.S., Truong, D. T., Dabire, R.K., Diabate, A., Levashina, E.A., Catteruccia, F. (2016). The reproductive tracts of two malaria vectors are populated by a core microbiome and by gender- and swarmenriched microbial biomarkers. Sci Rep, 6, 24207. 
Shane, J.L., Grogan, C.L., Cwalina, C., Lampe, D.J. (2018). Blood meal-induced inhibition of vector-borne disease by transgenic microbiota. Nat Commun, 9, 4127.

Shapiro, L.L.M., Whitehead, S.A., Thomas, M.B. (2017). Quantifying the effects of temperature on mosquito and parasite traits that determine the transmission potential of human malaria. PLoS Biol, 15, e2003489.

Sharma, P., Sharma, S., Maurya, R.K., Das De, T., Thomas, T., Lata, S., Singh, N., Pandey, K.C., Valecha, N., Dixit, R. (2014). Salivary glands harbor more diverse microbial communities than gut in Anopheles culicifacies. Parasit Vectors, 7, 235.

Shaw, W.R., Marcenac, P., Childs, L.M., Buckee, C.O., Baldini, F., Sawadogo, S.P., Dabire, R.K., Diabate, A., Catteruccia, F. (2016). Wolbachia infections in natural Anopheles populations affect egg laying and negatively correlate with Plasmodium development. Nat Commun, 7, 11772.

Short, S.M., Mongodin, E.F., MacLeod, H.J., Talyuli, O.A.C., Dimopoulos, G. (2017). Amino acid metabolic signaling influences Aedes aegypti midgut microbiome variability. PLoS Negl Trop Dis, 11, e0005677.

Siegel, J.P., Novak, R.J., Maddox, J.V. (1992). Effects of Ascogregarina barretti (Eugregarinida: Lecudinidae) infection on Aedes triseriatus (Diptera: Culicidae) in Illinois. J Med Entomol, 29, 968-973.

Simmons, T.W., Hutchinson, M.L. (2016). A critical review of all known published records for water mite (Acari: Hydrachnidiae) and mosquito (Diptera: Culicidae) parasitic associations from 1975 to present. J Med Entomol, 53, 737-752.

Smith, B.P., McIver, S.B. (1984). The impact of Arrenurus danbyensis Mullen (Acari: Prostigmata; Arrenuridae) on a population of Coquillettidia perturbans (Walker) (Diptera: Culicidae). Can J Zool, 62, 1121-1134

Soltani, A., Vatandoost, H., Oshaghi, M.A., Enayati, A.A., Chavshin, A.R. (2017). The role of midgut symbiotic bacteria in resistance of Anopheles stephensi (Diptera: Culicidae) to organophosphate insecticides. Pathog Glob Health, 111, 289-296.

Stecher, B., Hardt, W.D. (2011). Mechanisms controlling pathogen colonization of the gut. Curr Opin Microbiol, 14, 82-91.

Steyn, A., Roets, F., Botha, A. (2016). Yeasts associated with Culex pipiens and Culex theileri mosquito larvae and the effect of selected yeast strains on the ontogeny of Culex pipiens. Microb Ecol, 71, 747-760.

Stollar, V., Thomas, V.L. (1975). An agent in the Aedes aegypti cell line (Peleg) which causes fusion of Aedes albopictus cells. Virology, 64, 367-377.

Strand, M.R. (2018). Composition and functional roles of the gut microbiota in mosquitoes. Curr Opin Insect Sci, 28, 59-65.

Sulaiman, I. (1992). Infectivity and pathogenicity of Ascogregarina culicis (Eugregarinida: Lecudinidae) to Aedes aegypti (Diptera: Culicidae). J Med Entomol, 29, 1-4.

Suryawanshi, R.K., Patil, C.D., Borase, H.P., Narkhede, C.P., Salunke, B.K., Patil, S.V., (2015). Mosquito larvicidal and pupaecidal potential of prodigiosin from Serratia marcescens and understanding its mechanism of action. Pestic Biochem Physiol, 123, 49-55.

Tchioffo, M.T., Boissière, A., Abate, L., Nsango, S.E., Bayibeki, A.N., Awono-Ambene, P.H., Christen, R., Gimonneau, G., Morlais, I. (2015). Dynamics of bacterial community composition in the malaria mosquito's epithelia. Front Microbiol, 6, 1500.

Tchioffo, M.T., Abate, L., Boissière, A., Nsango, S.E., Gimonneau, G., Berry, A., Oswald, E., Dubois, D., Morlais, I. (2016). An epidemiologically successful Escherichia coli sequence type modulates Plasmodium falciparum infection in the mosquito midgut. Infect Genet Evol, 43, 22-30.
Terenius, O., Lindh, J.M., Eriksson-Gonzales, K., Bussiere, L., Laugen, A.T., Bergquist, H., Titanji, K., Faye, I. (2012). Midgut bacterial dynamics in Aedes aegypti. FEMS Microbiol Ecol, 80, 556-565.

Thongsripong, P., Chandler, J.A., Green, A.B., Kittayapong, P., Wilcox, B.A., Kapan, D.D., Bennett, S.N. (2018). Mosquito vector-associated microbiota: Metabarcoding bacteria and eukaryotic symbionts across habitat types in Thailand endemic for dengue and other arthropod-borne diseases. Ecol Evol, 8, 1352-1368.

Tseng, M. (2007). Ascogregarine parasites as possibe biocontrol agents of mosquitoes. J Am Mosq Control Assoc, 23, 30-34.

Valero-Jimenez, C.A., Debets, A.J., van Kan, J.A., Schoustra, S. E., Takken, W., Zwaan, B.J., Koenraadt, C.J. (2014). Natural variation in virulence of the entomopathogenic fungus Beauveria bassiana against malaria mosquitoes. Malar $J, 13,479$.

Valzania, L., Coon, K.L., Vogel, K.J., Brown, M.R., Strand, M. R. (2018). Hypoxia-induced transcription factor signaling is essential for larval growth of the mosquito Aedes aegypti. Proc Natl Acad Sci USA, 115, 457-465.

Valzano, M., Cecarini, V., Cappelli, A., Capone, A., Bozic, J., Cuccioloni, M., Epis, S., Petrelli, D., Angeletti, M., Eleuteri, A.M., Favia, G., Ricci, I. (2016). A yeast strain associated to Anopheles mosquitoes produces a toxin able to kill malaria parasites. Malar J, 15, 21.

van den Berg, H., Kelly-Hope, L.A., Lindsay, S.W. (2013). Malaria and lymphatic filariasis: The case for integrated vector management. Lancet Infect Dis, 13, 89-94.

Vasilakis, N., Tesh, R.B. (2015). Insect-specific viruses and their potential impact on arbovirus transmission. Curr Opin Virol, $15,69-74$.

Vega, F.E., Meyling, N.V., Luangsa-ard, J.J., Blackwell, M. (2012). Fungal entomopathogens, In: Insect Pathology, 2nd Edition, Academic Press, San Diego, pp. 171-220.

Verhulst, N.O., Andriessen, R., Groenhagen, U., Bukovinszkine Kiss, G., Schulz, S., Takken, W., van Loon, J.J., Schraa, G., Smallegange, R.C. (2010). Differential attraction of malaria mosquitoes to volatile blends produced by human skin bacteria. PloS One, 5, e15829.

Villegas, L.E.M., Campolina, T.B., Barnabe, N.R., Orfano, A.S., Chaves, B.A., Norris, D.E., Pimenta, P.F.P., Secundino, N.F. C. (2018). Zika virus infection modulates the bacterial diversity associated with Aedes aegypti as revealed by metagenomic analysis. PloS One, 13, e0190352.

Vogel, K.J., Valzania, L., Coon, K.L., Brown, M.R., Strand, M. R. (2017). Transcriptome sequencing reveals large-scale changes in axenic Aedes aegypti larvae. PLoS Negl Trop Dis, 11, e0005273.

Walker, E.D., Poirier, S.J., Veldman, W.T. (1987). Effects of Ascogregarina barretti (Eugregarinida: Lecudinidae) infection on emergence success, development time, and size of Aedes triseriatus (Diptera: Culicidae) in microcosms and tires. J Med Entomol, 24, 303-309.

Wang, Y., Gilbreath, T.M., 3rd, Kukutla, P., Yan, G., Xu, J. (2011). Dynamic gut microbiome across life history of the malaria mosquito Anopheles gambiae in Kenya. PloS One, 6, e24767.

Wang, S., Ghosh, A.K., Bongio, N., Stebbings, K.A., Lampe, D. J., Jacobs-Lorena, M. (2012). Fighting malaria with engineered symbiotic bacteria from vector mosquitoes. Proc Natl Acad Sci USA, 109, 12734-12739.

Wang, Y., Wang, Y., Zhang, J., Xu, W., Zhang, J., Huang, F.S. (2013). Ability of TEP1 in intestinal flora to modulate natural resistance of Anopheles dirus. Exp Parasitol, 134, 460-465. 
Wang, S., Dos-Santos, A.L.A., Huang, W., Liu, K.C., Oshaghi, M.A., Wei, G., Agre, P., Jacobs-Lorena, M. (2017). Driving mosquito refractoriness to Plasmodium falciparum with engineered symbiotic bacteria. Science, 357, 1399-1402.

Wei, G., Lai, Y., Wang, G., Chen, H., Li, F., Wang, S. (2017). Insect pathogenic fungus interacts with the gut microbiota to accelerate mosquito mortality. Proc Natl Acad Sci USA, 114, 5994-5999.

Werren, J.H., Baldo, L., Clark, M.E. (2008). Wolbachia: Master manipulators of invertebrate biology. Nat Rev Microbiol, 6, 741-751.

Whitfield, A.E., Falk, B.W., Rotenberg, D. (2015). Insect vectormediated transmission of plant viruses. Virology, 479-480, 278-289.

Wotton, R.S., Chaloner, D.T., Yardley, C.A., Merritt, R.W. (1997). Growth of Anopheles mosquito larvae on dietary microbiota in aquatic surface microlayers. Med Vet Entomol, 11, 65-70.
Yiallouros, M., Storch, V., Thiery, I., Becker, N. (1994). Efficacy of Clostridium bifermentans serovar Malaysia on target and nontarget organisms. J Am Mosq Control Assoc, 10, 51-55.

Yun, S.I., Lee, Y.M. (2014). Japanese encephalitis: The virus and vaccines. Hum Vaccin Immunother, 10, 263-279.

Zouache, K., Voronin, D., Tran-Van, V., Mousson, L., Failloux, A.B., Mavingui, P. (2009). Persistent Wolbachia and cultivable bacteria infection in the reproductive and somatic tissues of the mosquito vector Aedes albopictus. PloS One, 4, e6388.

Zouache, K., Raharimalala, F.N., Raquin, V., Tran-Van, V., Raveloson, L.H., Ravelonandro, P., Mavingui, P. (2011). Bacterial diversity of field-caught mosquitoes, Aedes albopictus and Aedes aegypti, from different geographic regions of Madagascar. FEMS Microbiol Ecol, 75, 377-389.

Zouache, K., Michelland, R.J., Failloux, A.B., Grundmann, G. L., Mavingui, P. (2012). Chikungunya virus impacts the diversity of symbiotic bacteria in mosquito vector. Mol Ecol, 21, 2297-2309.

Citation de l'article : Heu, K. et Gendrin, M. (2018). Le microbiote de moustique et son influence sur la transmission vectorielle.

Biologie Aujourd'hui, 212, 119-136 